\title{
Estimating the Return to Schooling: Progress on Some Persistent Econometric Problems
}

\author{
David Card \\ Econometrica, Vol. 69, No. 5. (Sep., 2001), pp. 1127-1160.
}

Stable URL:

http://links.jstor.org/sici?sici=0012-9682\%28200109\%2969\%3A5\%3C1127\%3AETRTSP\%3E2.0.CO\%3B2-Q

Econometrica is currently published by The Econometric Society.

Your use of the JSTOR archive indicates your acceptance of JSTOR's Terms and Conditions of Use, available at http://www.jstor.org/about/terms.html. JSTOR's Terms and Conditions of Use provides, in part, that unless you have obtained prior permission, you may not download an entire issue of a journal or multiple copies of articles, and you may use content in the JSTOR archive only for your personal, non-commercial use.

Please contact the publisher regarding any further use of this work. Publisher contact information may be obtained at http://www.jstor.org/journals/econosoc.html.

Each copy of any part of a JSTOR transmission must contain the same copyright notice that appears on the screen or printed page of such transmission.

The JSTOR Archive is a trusted digital repository providing for long-term preservation and access to leading academic journals and scholarly literature from around the world. The Archive is supported by libraries, scholarly societies, publishers, and foundations. It is an initiative of JSTOR, a not-for-profit organization with a mission to help the scholarly community take advantage of advances in technology. For more information regarding JSTOR, please contact support@jstor.org. 


\title{
ESTIMATING THE RETURN TO SCHOOLING: PROGRESS ON SOME PERSISTENT ECONOMETRIC PROBLEMS
}

\author{
BY DAVID CARD ${ }^{1}$
}

\begin{abstract}
This paper reviews a set of recent studies that have attempted to measure the causal effect of education on labor market earnings by using institutional features of the supply side of the education system as exogenous determinants of schooling outcomes. A simple theoretical model that highlights the role of comparative advantage in the optimal schooling decision is presented and used to motivate an extended discussion of econometric issues, including the properties of ordinary least squares and instrumental variables estimators. A review of studies that have used compulsory schooling laws, differences in the accessibility of schools, and similar features as instrumental variables for completed education, reveals that the resulting estimates of the return to schooling are typically as big or bigger than the corresponding ordinary least squares estimates. One interpretation of this finding is that marginal returns to education among the low-education subgroups typically affected by supply-side innovations tend to be relatively high, reflecting their high marginal costs of schooling, rather than low ability that limits their return to education.
\end{abstract}

KEYWORDS: Returns to education, ability bias, random coefficients.

OVER THE PAST DECADE there has been a resurgence of interest in the study of the causal links between education and labor market success. Part of this renewed interest stems from a rise in the "return" to education, especially in the U.S. labor market, and a search for the causes of the growing disparities between more and less-educated workers (Katz and Autor (1999)). Part is attributable to the revival of interest in the determinants of economic growth, and a new focus on the role of human capital in the development process (Topel (1999)). Finally, many countries are experiencing rapid growth in their secondary and post-secondary school enrollment rates, leading to a concern about the relative costs and benefits of higher education for those who were not previously receiving it.

In addition to the stimulus provided by these key substantive issues, interest in the joint structure of education and earnings has been heightened by the belief that some progress has been made-and more may follow-in the very difficult task of uncovering the causal effect of education in labor market outcomes. The basic idea underlying this new thrust of research is that institutional features of the education system can be used to form credible instrumental variables for individual schooling outcomes that can cut through the Gordian Knot of endogenous schooling and unobserved ability. The use of supply-side variables to help resolve identification problems on the demand side of the

\footnotetext{
${ }^{1}$ Fisher-Schultz Lecture delivered to the European Meeting of the Econometric Society, September, 1998. I am grateful to Joshua Angrist, Michael Boozer, Ken Chay, Andrew Hildreth, Alan Krueger, and a co-editor for comments on earlier versions of this material, and to James Powell for helpful discussions.
} 
education market is a natural outgrowth of standard econometric practice. Nevertheless, the idea attracted very little attention in the first wave of microeconometric studies of education and earnings in the 1960's and 1970's. Indeed, it is one of the few methodological issues that is not discussed thoroughly in Griliches' (1977) landmark survey of the first-wave literature.

In this paper, I present a survey and partial synthesis of the recent literature that has used "supply-side" features of the education system to help identify the causal effect of education. In interpreting this literature I believe it is helpful to work from a theoretical and econometric viewpoint that explicitly recognizes the possibility that returns to education may vary across the population, depending on such characteristics as family background and ability. This perspective helps to reconcile various findings in the literature, and also provides a useful framework for generating new hypotheses and insights about the connection between education and earnings.

The paper begins with the presentation of a simple theoretical model of endogenous schooling. This model is then used to motivate an extended discussion of various econometric issues. Finally, I present a selective review of the recent literature on estimating the economic returns to education, drawing on studies of the U.S. and other developed economies, as well as a handful of studies of developing economies.

\section{A MODEL OF ENDOGENOUS SCHOOLING}

Most of the conceptual issues underlying the interpretation of recent studies of the return to education can be illustrated in the framework of a simple model that builds on Becker (1967). In such a model individuals face a market opportunity locus that gives the level of earnings associated with alternative schooling choices, and reach an optimal schooling decision by balancing the benefits of higher schooling (which are reaped over the lifecycle) against the costs (which are born early on). Traditionally, it is assumed that individuals seek to maximize the discounted present value of earnings, net of schooling costs (see, e.g., Willis (1986)). This is appropriate if people can borrow or lend at a fixed interest rate, and if they are indifferent between attending school or working during their late teens and early twenties. More generally, however, different individuals may have different aptitudes and tastes for schooling relative to work, and this variation may lead to differences in the optimal level of schooling across individuals.

Assume that individuals have an infinite planning horizon that starts at the minimum school-leaving age $(t=0)$ and that they accrue a flow of utility in period $t$ that depends on consumption $c(t)$ in period $t$ and on whether they are in school (and working part time) or out of school and working full time. Utility while in school is $u(c(t))-\phi(t)$ and utility out of school is $u(c(t))$, where $u(\cdot)$ is an increasing concave function and $\phi(t)$ is a convex function that reflects the 
relative disutility of school versus work for the $t$ th year of schooling. ${ }^{2}$ Finally, assume that individuals discount future utility flows at a subjective discount rate $\rho$, and make a once-for-all decision on when to leave school. ${ }^{3}$ Lifecycle utility, conditional on schooling $S$ and a given consumption profile is

$$
V(S, c(t))=\int_{0}^{S}(u(c(t)-\phi(t))) e^{-\rho t} d t+\int_{S}^{\infty} u(c(t)) e^{-\rho t} d t .
$$

Let $y(S, t)$ denote real earnings at age $t$ of an individual who has completed $S$ years of post-compulsory schooling (with $t \geq S \geq 0$ ). ${ }^{4}$ Assume that individuals who are in school at time $t$ work part time and earn $p(t)$, and pay tuition costs of $T(t)$. Moreover, assume that the individual can borrow or lend freely at a fixed interest rate $R$. Under these conditions the intertemporal budget constraint is

$$
\int_{0}^{\infty} c(t) e^{-R t} d t=\int_{0}^{S}(p(t)-T(t)) e^{-R t} d t+\int_{S}^{\infty} y(S, t) e^{-R t} d t
$$

An individual's optimal schooling choice and optimal consumption path maximize

$$
\begin{aligned}
\Omega(S, c(t), \lambda)= & V(S, c(t)) \\
& -\lambda\left\{\int_{0}^{\infty} c(t) e^{-R t} d t-\int_{0}^{S}(p(t)-T(t)) e^{-R t} d t\right. \\
& \left.-\int_{S}^{\infty} y(S, t) e^{-R t} d t\right\} .
\end{aligned}
$$

The derivative of this expression with respect to $S$ is

$$
\Omega_{S}(S, c(t), \lambda)=\lambda e^{-R S}\{M B(S)-M C(S)\},
$$

where

$$
M B(S)=\int_{0}^{\infty} \partial y(S, S+\tau) / \partial S e^{-R \tau} d \tau
$$

\footnotetext{
${ }^{2}$ In principle $\phi(S)$ can be negative (if schooling is preferred to work) or positive. For simplicity I am treating hours of work both during and after the completion of school as exogenous.

${ }^{3}$ Card and Lemieux (2000) examine school-leaving behavior of young men and women in the National Longitudinal Survey of Youth and find that about one quarter of those who leave school return at some point in the future. However, more than half of the returners complete one semester or less of additional schooling. Angrist and Newey (1991) study the earnings changes associated with education increments acquired after young men first enter the labor market on a full-time basis.

${ }^{4}$ The earnings function $y(S, t)$ may reflect productivity and/or signaling effects or higher schooling. As noted below, some recent studies identify the causal effect of education by comparing schooling and earnings differences across cohorts or other groups. In the presence of signaling effects the "returns" to schooling estimated in this way may differ from the earnings gains expected by any given individual in the group.
} 
represents the marginal benefit of the $S$ th unit of schooling (expressed in period $S$ dollars), and

$$
M C(S)=y(S, S)-p(S)+T(S)+1 / \lambda e^{-(\rho-R) S} \phi(S)
$$

represents the marginal cost of the $S$ th unit of schooling (also in period $S$ dollars). Notice that if $\phi(S)=0$, then $M C(S)$ is independent of preferences and depends only on the net opportunity cost of schooling $(y(S, S)-p(S))$ plus tuition costs $(T(S))$. Otherwise, $M C(S)$ also includes a term capturing the relative disutility of school versus work.

Assuming that $M C(S)$ rises faster than $M B(S)$, a necessary and sufficient condition for an optimal schooling choice is that $M C(S)=M B(S)$. To proceed, assume that $\log$ earnings are additively separable in education and years of post-schooling experience (Mincer (1974)). Then the earnings function can be written as $y(S, t)=f(S) h(t-S)$ (with $h(0)=1$ ), and the marginal benefit of the $S$ th unit of schooling is

$$
M B(S)=f^{\prime}(S) \int_{0}^{\infty} h(\tau) e^{-R \tau} d \tau=f^{\prime}(S) H(R),
$$

where $H(R)$ is a decreasing function of the interest rate. In particular, if earnings are fixed after the completion of schooling (i.e., $h(t)=1$ for all $t$ ) then $H(R)=1 / R$. More generally, if earnings follow a concave lifecycle profile, then $H(R)=1 /(R-g)$, where $g$ is the constant growth rate that is "equivalent" to the lifecycle profile (i.e. $\int_{0}^{\infty} e^{g \tau} \times e^{-R \tau} d \tau=\int_{0}^{\infty} h(\tau) e^{-R \tau} d \tau$ ).

Under separability, the marginal costs and marginal benefits of additional schooling are equated when

$$
\begin{aligned}
f^{\prime}(S) / f(S)= & 1 / H(R) \\
& \times\left\{1+(T(S)-p(S)) / f(S)+1 / \lambda e^{-(\rho-R) S} \phi(S) / f(S)\right\} .
\end{aligned}
$$

The left-hand side of this expression is the proportional increase in earnings (per year) associated with the $S$ th unit of schooling. The right-hand side is the annuitized marginal cost of the $S$ th unit of schooling, expressed as a fraction of foregone earnings. Ignoring tuition costs and earnings while in school, and any disutility of schooling relative to work, and assuming that earnings are fixed over the lifecycle, this expression reduces to the well-known condition $f^{\prime}(S) / f(S)=R$ (see, e.g., Willis (1986)), which implies that individuals invest in schooling until the marginal return is equal to the interest rate.

To consider a more general case, assume that $u(c(t))=\log c(t)$. Then the first order conditions for an optimal consumption profile, together with the lifecycle budget constraint, imply that

$$
1 / \lambda=\rho\left\{e^{-R S} f(S) H(R)+\int_{0}^{S}(p(t)-T(t)) e^{-R t} d t\right\} \equiv \rho W(S),
$$

where $W(S)$ is the value of lifecycle wealth associated with the schooling choice $S$. Assume further that part-time earnings while in school are approximately 
equal to tuition costs (i.e., $T(S) \approx p(S)$ ). Then an optimal schooling choice satisfies the condition

$$
f^{\prime}(S) / f(S)=R-g+\rho e^{-\rho S} \phi(S) \equiv d(S) .
$$

Relative to the baseline case that ignores preferences for school versus work and post-schooling earnings growth, this expression introduces two additional considerations to the determination of optimal schooling. First, the interest rate must be adjusted to reflect lifecycle earnings growth. Second, marginal cost has to account for the relative disutility of attending the $S$ th year of schooling. ${ }^{5}$

Inspection of equation (1) suggests that individual heterogeneity in the optimal schooling choice can arise from one of two sources: differences in the economic benefits of schooling, represented by heterogeneity in the marginal return to schooling $f^{\prime}(S) / f(S)$; or differences in the marginal costs of schooling, represented by heterogeneity in $d(S)$. A simple specification of these heterogeneity components is

$$
\begin{aligned}
& f^{\prime}(S) / f(S)=b_{i}-k_{1} S, \\
& d(S)=r_{i}+k_{2} S,
\end{aligned}
$$

where $b_{i}$ and $r_{i}$ are random variables with means $\bar{b}$ and $\bar{r}$ and second moments $\sigma_{b}^{2}, \sigma_{r}^{2}$, and $\sigma_{b r}$, and $k_{1}$ and $k_{2}$ are nonnegative constants. ${ }^{6}$ These assumptions imply that the optimal schooling choice is linear in the individual-specific heterogeneity terms:

$$
S_{i}=\left(b_{i}-r_{i}\right) / k,
$$

where $k=k_{1}+k_{2}$ is assumed to be strictly positive.

At the equilibrium level of schooling described by equation (4) individual $i$ 's marginal return to schooling is

$$
\beta_{i} \equiv b_{i}-k_{1} S_{i}=b_{i}\left(1-k_{1} / k\right)+r_{i} k_{1} / k .
$$

This model gives rise to a nondegenerate distribution of marginal returns across the population unless one of two conditions is satisfied: $k_{2}=0$ and $r_{i}=\bar{r}$ for all

${ }^{5} \mathrm{~A}$ more complex expression arises if part time earnings while in school do not fully offset tuition. For example, if tuition costs and part time earnings are constant $(T(t)=T ; p(t)=p)$, it can be shown that

$$
\begin{aligned}
d(S)= & (R-g) \times(1+(T-p) / f(S))+\rho e^{-\rho S} \phi(S) \\
& \times\left[1-\left(e^{R S}-1\right) \times(R-g) / R \times(T-p) / f(S)\right] .
\end{aligned}
$$

If tuition costs are small relative to lifetime earnings, the term in square brackets is close to 1 , implying

$$
d(S) \approx(R-g) \times(1+(T-p) / f(S))+\rho e^{-\rho S} \phi(S) .
$$

\footnotetext{
${ }^{6}$ Note that if individuals are indifferent between school and work, then $k_{2}=0$ and $r_{i}=R-g$. In this case variation in $r_{i}$ arises because individuals face different interest rates, or differential growth in lifecycle earnings. More generally, $\phi(S)$ is a convex function of $S$ and equation (3) can be regarded as a linear approximation to $d(S)$.
} 
$i$ (a situation to which Becker (1967) referred as "equality of opportunity"); or $k_{1}=0$ and $b_{i}=\bar{b}$ for all $i$ (a case to which Becker referred as "equality of ability"). ${ }^{7}$ The average marginal return to education is $\bar{\beta}=E\left[\beta_{i}\right]=E\left[b_{i}-k_{1} S_{i}\right]$ $=\bar{b}-k_{1} \bar{S}$. This is the expected increase in average log earnings if a random sample of the population acquired an additional unit of education. As will be discussed in more detail below, $\bar{\beta}$ is not necessarily the relevant marginal return for evaluating any particular schooling intervention. Nevertheless, it forms a useful benchmark against which to compare the probability limit of various estimators of the return to schooling.

For the labor market as a whole the distribution of marginal returns to schooling is endogenous: a greater supply of highly-educated workers will presumably lower $\bar{b}$, and might also affect other characteristics of the distribution of $b_{i}{ }^{8}$. From the perspective of a cohort of young adults deciding on their education, however, the distribution of returns to education is arguably exogenous. I therefore prefer to interpret equation (4) as a partial equilibrium description of the relative education choices of a cohort, given the institutional environment and economic conditions that prevailed during their late teens and early twenties. Differences across cohorts in these background factors will lead to further variation in the distribution of marginal returns to education in the population as a whole.

\section{ECONOMETRIC ISSUES RAISED BY ENDOGENOUS SCHOOLING}

\section{A. OLS Estimates of the Return to Schooling}

To understand the implications of the preceding model for observed schooling and earnings outcomes, note that equation (2) implies a model for log earnings of the form

$$
\log y_{i}=\alpha_{i}+b_{i} S_{i}-\frac{1}{2} k_{1} S_{i}^{2}
$$

where $\alpha_{i}$ is a person-specific constant of integration. ${ }^{9}$ This is a somewhat more general version of the semi-logarithmic functional form adopted in Mincer (1974) and hundreds of subsequent studies. In particular, individual heterogeneity is allowed to affect both the intercept of the earnings equation (via $\alpha_{i}$ ) and the slope of the earnings-schooling relation (via $b_{i}$ ). It is convenient to rewrite this equation as

$$
\log y_{i}=a_{0}+\bar{b} S_{i}-\frac{1}{2} k_{1} S_{i}^{2}+a_{i}+\left(b_{i}-\bar{b}\right) S_{i},
$$

\footnotetext{
${ }^{7}$ There is also an uninteresting case in which both $b_{i}$ and $r_{i}$ are degenerate.

${ }^{8}$ See Freeman (1986) and Willis (1986) for some discussion of the general equilibrium implications of optimal schooling models.

${ }^{9}$ Under the assumption of separability, the lifecycle earnings function also contains an additive experience term, which I will ignore for notational simplicity.
} 
where $a_{i} \equiv \alpha_{i}-a_{0}$ has mean 0. Equations (4) and (5) together describe a two-equation system for schooling and earnings in terms of the underlying random variables $a_{i}, b_{i}$, and $r_{i}$.

Ignoring other covariates (or assuming these have already been conditioned out) it is straightforward to derive the implications of this model for conventional ordinary least squares (OLS) estimates of the return to schooling. To proceed, consider the linear projections of $a_{i}$ and $\left(b_{i}-\bar{b}\right)$ on observed schooling:

$$
\begin{aligned}
& a_{i}=\lambda_{0}\left(S_{i}-\bar{S}\right)+u_{i}, \\
& b_{i}-\bar{b}=\psi_{0}\left(S_{i}-\bar{S}\right)+v_{i},
\end{aligned}
$$

where $\bar{S}$ represents the mean of schooling and $E\left[S_{i} u_{i}\right]=E\left[S_{i} v_{i}\right]=0$. Substituting these expressions into (5), the earnings function can be written as

$$
\log y_{i}=\text { constant }+\left(\bar{b}+\lambda_{0}-\psi_{0} \bar{S}\right) S_{i}+\left(\psi_{0}-\frac{1}{2} k_{1}\right) S_{i}^{2}+u_{i}+v_{i} S_{i} .
$$

In general the orthogonality of $v_{i}$ and $S_{i}$ does not imply that $E\left[v_{i} S_{i}^{2}\right]=0$ : thus, the residual component $v_{i} S_{i}$ may be correlated with schooling. However, if the third central moments of the joint distribution of $b_{i}$ and $r_{i}$ are all zero, then $v_{i} S_{i}$ will be uncorrelated with $S_{i}{ }^{10}$ Moreover, in this case $E\left[\left(S_{i}-\bar{S}\right)^{3}\right]=0$, implying that the linear projection of $S_{i}^{2}$ on $S_{i}$ has slope $2 \bar{S}$. Under this assumption the probability limit of the ordinary least squares (OLS) regression coefficient $b_{\text {ols }}$ from a regression of log earnings on schooling is

$$
\begin{aligned}
\operatorname{plim} b_{o l s} & =\bar{b}+\lambda_{0}-\psi_{0} \bar{S}+2 \bar{S} \times\left(\psi_{0}-\frac{1}{2} k_{1}\right) \\
& =\bar{b}-k_{1} \bar{S}+\lambda_{0}+\psi_{0} \bar{S} \\
& =\bar{\beta}+\lambda_{0}+\psi_{0} \bar{S} .
\end{aligned}
$$

More generally equation (7) includes an additional term that depends on the third moments of $b_{i}$ and $r_{i}{ }^{11}$

\footnotetext{
${ }^{10}$ Alternatively, if the orthogonality condition $E\left[S_{i} v_{i}\right]=0$ is replaced by the assumption $E\left[v_{i} \mid S_{i}\right]$ $=0$ (i.e., that the conditional expectation of $b_{i}$ is linear in $S_{i}$ ), then $E\left[v_{i} S_{i}^{2}\right]=E\left\{E\left[v_{i} S_{i}^{2} \mid S_{i}\right]\right\}=0$.

${ }^{11}$ In the general case the linear projection of $S_{i}^{2}$ on $S_{i}$ has slope

$$
\begin{aligned}
& 2 \bar{S}+E\left[\left(S_{i}-\bar{S}\right)^{3}\right] / \operatorname{var}\left[S_{i}\right], \text { and } \\
& \operatorname{cov}\left[v_{i} S_{i}, S_{i}\right]=E\left[\left(b_{i}-\bar{b}\right)\left(S_{i}-\bar{S}\right)^{2}\right]-\psi_{0} E\left[\left(S_{i}-\bar{S}\right)^{3}\right] .
\end{aligned}
$$
}

Taking these expressions into consideration, equation (7) includes another term:

$$
E\left[\left(b_{i}-b\right)\left(S_{i}-S\right)^{2}\right] / \operatorname{var}\left[S_{i}\right]-\frac{1}{2} k_{1} E\left[\left(S_{i}-\bar{S}\right)^{3}\right] / \operatorname{var}\left[S_{i}\right]
$$


Equation (7) generalizes the conventional analysis of ability bias in the relationship between schooling and earnings. ${ }^{12}$ Suppose that there is no heterogeneity in the marginal benefits of schooling (i.e., $b_{i}=\bar{b}$ ) and that log earnings are linear in schooling (i.e. $k_{1}=0$ ). Then (7) implies that

$$
\operatorname{plim} b_{o l s}-\bar{b}=\lambda_{0},
$$

which is the standard expression for the asymptotic bias in the estimated return to schooling that arises by applying the omitted variables formula to an earnings model with a constant schooling coefficient $\bar{b}$. According to the model presented here, this bias arises through the correlation between the ability component $a_{i}$ and the marginal cost of schooling $r_{i}$. If marginal costs are lower for people who would tend to earn more at any level of schooling, then $\sigma_{r a}<0$, implying that $\lambda_{0}>0$.

If both the intercept and slope of the earnings function vary across individuals, then the situation is a little more complex. Since people with a higher return to education have an incentive to acquire more schooling, a cross-sectional regression of earnings on schooling is likely to yield an upward-biased estimate of the average marginal return to schooling, even ignoring variation in the intercepts of the earnings function. The magnitude of this endogeneity or comparative advantage bias depends on the relative importance of $b_{i}$ in determining the overall variance of schooling outcomes. Specifically, the fraction of the variance of schooling attributable to differences in the slope of the earnings-schooling relation (as opposed to differences in tastes or access to funds) can be defined as

$$
f=\frac{\sigma_{b}^{2}-\sigma_{b r}}{\left(\sigma_{b}^{2}+\sigma_{r}^{2}-2 \sigma_{b r}\right)} .
$$

Assuming that $\sigma_{b r} \leq 0$ (i.e., that the marginal benefits of schooling are no higher for people with higher marginal costs of schooling), $f$ is bounded between 0 and 1. The projection coefficient defined in equation (6b) is $\psi_{0}=\operatorname{cov}\left[b_{i}, S_{i}\right] / \operatorname{var}\left[S_{i}\right]$ $=k \cdot f$. Thus, the endogeneity bias component in the OLS estimator is $\psi_{0} \bar{S}=k \cdot f$ $\cdot \bar{S}$, which is proportional to $f$. Even ignoring the traditional ability bias term $\lambda_{0}$, $b_{o l s}$ is therefore an upward-biased estimate of $\bar{\beta}$, with a larger bias the more important are the comparative advantage incentives that lead individuals with higher returns to schooling to acquire more schooling.

The analysis so far has ignored any problems arising from the mismeasurement of schooling. Griliches (1977) argued that measurement errors in schooling would lead to downward bias in the OLS estimate of the effect of schooling on earnings that could partially offset any upward ability biases. To see this, assume that observed schooling $\left(S_{i}^{0}\right)$ differs from true schooling $\left(S_{i}\right)$ by an additive

\footnotetext{
${ }^{12}$ Throughout this paper I use the term "bias" to refer to the difference between the probability limit of an estimator and some target parameter: typically the average marginal return to schooling in the population under study.
} 
error,

$$
S_{i}^{0}=S_{i}+\epsilon_{i}
$$

where $\epsilon_{i}$ has mean 0 , variance $\sigma_{\epsilon}^{2}$, and is uncorrelated with earnings. Assuming that equation (7) describes the probability limit of an OLS estimator based on true schooling, the use of observed schooling will yield an OLS estimator with

$$
\operatorname{plim}\left(b_{o l s}\right)=R_{0}\left\{\bar{\beta}+\lambda_{0}+\psi_{0} \bar{S}\right\},
$$

where $R_{0} \equiv \operatorname{cov}\left[S_{i}^{0}, S_{i}\right] / \operatorname{var}\left[S_{i}^{0}\right]$ is the reliability of observed schooling (i.e., the slope of the linear projection of true schooling on observed schooling). If the measurement errors are orthogonal to true schooling, then $R_{0}=\operatorname{var}\left[S_{i}\right] /$ $\left\{\operatorname{var}\left[S_{i}\right]+\sigma_{\epsilon}^{2}\right\}<1$, and OLS using observed schooling will be downward-biased relative to the case of no measurement error. Research in the U.S. over the past three decades has concluded that the reliability of self-reported schooling is 85-90 percent (Angrist and Krueger (1999, Table 9)), implying that the downward bias is on the order of 10-15 percent-enough to offset a modest upward ability bias.

It is worth noting that equation (8) is valid regardless of whether the measurement errors are orthogonal to true schooling or not. With correlated measurement errors, however, the reliability of observed schooling may be greater or less than 1. More importantly, the standard procedure for estimating $R_{0}$, based on the correlation between two alternative survey measures of schooling, assumes that $E\left[S_{i} \epsilon_{i}\right]=0$. Since schooling is measured as a discrete variable with fixed upper and lower limits, this cannot be literally true: individuals with the highest level of schooling cannot report positive errors, while those with the lowest level cannot report negative errors. Mean-regressive measurement error is likely to lead conventional procedures to understate the actual reliability of schooling. ${ }^{13}$ Thus, the actual attenuation of an OLS estimate may be less than 10 percent.

\section{B. Instrumental Variables Estimates of the Return to Schooling}

Social scientists have long recognized that the cross-sectional correlation between education and earnings may differ from the true causal effect of education. A standard solution to the problem of causal inference is the method of instrumental variables (IV): a researcher posits the existence of an observable covariate that affects schooling choices but is uncorrelated with (or even independent of) the ability factors $a_{i}$ and $b_{i}$. Recently, much attention has focused on supply-side sources of variation in schooling, attributable to such

\footnotetext{
${ }^{13}$ Suppose that there are two equally noisy measures $x_{1}$ and $x_{2}$ of a true quantity $x$, with $x_{j}=x+e_{j}$. Assume that the measurement errors are mean-regressive: $E\left[e_{j} \mid x\right]=-\alpha(x-\mu)$, for $j=1,2$, where $\mu$ is the mean of $x$. Let $v_{j}=e_{j}-E\left[e_{j} \mid x\right]$ and assume that $v_{j}$ 's are uncorrelated. Traditionally, reliability is measured by the correlation of the two noisy measures: $\rho=$ $\operatorname{cov}\left[x_{1}, x_{2}\right] / \operatorname{var}\left[x_{1}\right]$. Under the preceding assumptions, however, $\rho=(1-\alpha) R$, implying that $R>\rho$.
} 
features as the minimum school-leaving age, tuition costs, or the geographic proximity of schools. As in standard market settings, variables from the supply side are an obvious source of identifying information for estimating demand-side parameters.

To proceed, suppose that the marginal cost component $r_{i}$ is linearly related to a set of observable variables $Z_{i}$ :

$$
r_{i}=Z_{i} \pi_{1}+\eta_{i},
$$

where $\eta_{i}$ incorporates other unobserved taste and cost factors, and $E\left[\eta_{i} Z_{i}\right]=0$. The optimal schooling choice is

$$
\begin{aligned}
S_{i} & =\left(b_{i}-r_{i}\right) / k \\
& =Z_{i} \pi+\xi_{i},
\end{aligned}
$$

where $Z_{i} \pi=\bar{b} / k-Z_{i} \pi_{1} / k$ and $\xi_{i} \equiv\left(b_{i}-\bar{b}-\eta_{i}\right) / k$. If $a_{i}$ is the only individual-specific component of ability, then equations (4') and (5) constitute a standard simultaneous equations system and the assumption that $Z_{i}$ is uncorrelated with ability $\left(E\left[a_{i} Z_{i}\right]=0\right)$ is sufficient to ensure that an IV estimator based on $Z_{i}$ will yield a consistent estimate of the average return to schooling $\bar{b}^{14}$ If there is heterogeneity in returns to education, however, somewhat stronger assumptions are needed for IV to yield a consistent estimate of the average return to schooling, since the residual earnings component $\left(b_{i}-\bar{b}\right) S_{i}$ may be correlated with $Z_{i}$ even if $Z_{i}$ is orthogonal to $b_{i}$.

One sufficient condition is that $Z_{i}$ is independent of individual abilities $\left(a_{i}, b_{i}\right)$ and the reduced form schooling residual $\xi_{i} \cdot{ }^{15}$ In this case

$$
\begin{aligned}
E\left[\log y_{i} \mid Z_{i}\right]= & E\left[a_{0}+\bar{b} S_{i}-\frac{1}{2} k_{1} S_{i}^{2}+a_{i}+\left(b_{i}-\bar{b}\right) S_{i} \mid Z_{i}\right] \\
= & a_{0}+E\left[\bar{b}\left(Z_{i} \pi+\xi_{i}\right) \mid Z_{i}\right]-\frac{1}{2} k_{1} E\left[\left(Z_{i} \pi+\xi_{i}\right)^{2} \mid Z_{i}\right] \\
& +E\left[a_{i} \mid Z_{i}\right]+E\left[\left(b_{i}-\bar{b}\right)\left(Z_{i} \pi+\xi_{i}\right) \mid Z_{i}\right] \\
= & a_{0}+\bar{b} Z_{i} \pi-\frac{1}{2} k_{1}\left(Z_{i} \pi\right)^{2}-\frac{1}{2} k_{1} E\left[\xi_{i}^{2} \mid Z_{i}\right] \\
& +E\left[\left(b_{i}-\bar{b}\right) \xi_{i} \mid Z_{i}\right] .
\end{aligned}
$$

Under independence the two conditional expectations in this expression are constant for all values of $Z_{i}$, implying that the coefficients from the second stage of a modified two-stage least squares system (in which actual schooling and its square are replaced by predicted schooling and its square) will be consistent for $\bar{b}$ and $-\frac{1}{2} k_{1}$, respectively. Thus the average marginal return to schooling can be consistently estimated by IV.

\footnotetext{
${ }^{14}$ If earnings are a quadratic function of schooling, then $Z_{i}$ and its square can be used as instruments.

${ }^{15}$ This case is considered by Heckman and Vytlacil (1998).
} 
A slightly weaker set of sufficient conditions for consistency was proposed by Wooldridge (1997). In particular, suppose that the individual-specific heterogeneity components are mean-independent of $Z$ (i.e., $E\left[\eta_{i} \mid Z_{i}\right]=0, E\left[a_{i} \mid Z_{i}\right]=$ 0 , and $\left.E\left[\left(b_{i}-\bar{b}\right) \mid Z_{i}\right]=0\right)$, and that two additional assumptions are satisfied:

$$
\begin{aligned}
& E\left[\xi_{i}^{2} \mid Z_{i}\right]=\sigma_{\xi}^{2}, \\
& E\left[\left(b_{i}-\bar{b}\right) \mid S_{i}, Z_{i}\right]=\psi_{0} \xi_{i} .
\end{aligned}
$$

Equation (9a) requires that the reduced form schooling residual in equation (4') be homoskedastic, while equation (9b) specifies that the conditional expectation of individual ability $\left(b_{i}\right)$ be linear in the schooling residual. ${ }^{16}$ Under these assumptions the conditional expectation of the residual earnings component attributable to heterogeneity in returns is

$$
\begin{aligned}
E\left[\left(b_{i}-\bar{b}\right) S_{i} \mid Z_{i}\right] & =E\left[E\left[\left(b_{i}-\bar{b}\right) S_{i} \mid S_{i}, Z_{i}\right] \mid Z_{i}\right] \\
& =\psi_{0} \sigma_{\xi}^{2},
\end{aligned}
$$

implying that

$$
E\left[\log y_{i} \mid Z_{i}\right]=a_{0}+\bar{b} \cdot Z_{i} \pi-\frac{1}{2} k_{1}\left(Z_{i} \pi\right)^{2}+\left(\psi_{0}-\frac{1}{2} k_{1}\right) \sigma_{\xi}^{2} .
$$

Again, this condition ensures that the probability limits of the second-stage coefficients of predicted education and its square in the IV procedure are $\bar{b}$ and $-\frac{1}{2} k_{1}$, respectively. ${ }^{17}$

Unfortunately, the assumptions that $Z_{i}$ is independent of ability and the reduced form schooling residual $\xi_{i}$, or the slightly weaker assumptions in (9a) and (9b), are likely to be violated when $Z_{i}$ is a variable representing exposure to different institutional structures on the supply side of the education system. The reason is that the entire mapping between ability and schooling is likely to be affected by a change in educational institutions, leading to a systematic correlation between $\left(b_{i}-\bar{b}\right) S_{i}$ and $Z_{i}$. To illustrate this point in the context of the model, consider IV estimation based on a schooling reform that leads to a proportional reduction in the marginal cost of schooling for students in a specific set of schools (or in a specific cohort). Assume that the joint distribution of abilities and tastes $\left(a_{i}, b_{i}, r_{i}\right)$ is the same for individuals who attended the reformed schools (indexed by $Z_{i}=1$ ) and those who did not (indexed by $Z_{i}=0$ ), but that in the reformed schools the optimal school choice is given by

$$
S_{i}=\left(b_{i}-\theta r_{i}\right) / k,
$$

${ }^{16}$ Equation (6b) above specifies the linear projection of $b_{i}$ on schooling as $\psi_{0}\left(S_{i}-E\left[S_{i}\right]\right)$. If the conditional expectation is linear, it has the same coefficient as the linear projection.

${ }^{17}$ If $k_{1}=0$ (i.e., earnings are a linear function of schooling) Wooldridge shows that assumptions (9a) and (9b) can be replaced by $E\left[\left(b_{i}-\bar{b}\right)^{2} \mid Z_{i}\right]=\sigma_{b}^{2}$, and $E\left[\xi_{i} \mid b_{i}, Z_{i}\right]=\rho_{1}\left(b_{i}-\bar{b}\right)$. Under these assumptions, $E\left[\left(b_{i}-\bar{b}\right) S_{i} \mid Z_{i}\right]=\rho_{1} \sigma_{b}^{2}$, implying that the heterogeneity component of the earnings residual is uncorrelated with the instruments. 
where $\theta<1$. Let $r_{i}=\bar{r}+\eta_{i}$, and observe that among individuals who attended the unreformed schools,

$$
\begin{aligned}
S_{i} & =(\bar{b}-\bar{r}) / k+\left(b_{i}-\bar{b}-\eta_{i}\right) / k \\
& =\pi_{0}+\xi_{i 0},
\end{aligned}
$$

whereas among individuals who attended reformed schools,

$$
\begin{aligned}
S_{i} & =(\bar{b}-\bar{r}) / k+(1-\theta) \bar{r} / k+\left(b_{i}-\bar{b}-\theta \eta_{i}\right) / k \\
& =\pi_{0}+\pi_{1}+\xi_{i 1} .
\end{aligned}
$$

The reduced form schooling equation is therefore

$$
S_{i}=\pi_{0}+Z_{i} \pi_{1}+\xi_{i}
$$

where $\xi_{i}=\left(1-Z_{i}\right) \xi_{i 0}+Z_{i} \xi_{i 1}$. Since the schooling reform lowers the effect of cost differences in the optimal schooling decision, $\operatorname{var}\left[\xi_{i} \mid Z_{i}=1\right] \leq \operatorname{var}\left[\xi_{i} \mid Z_{i}=\right.$ 0 ], violating independence and the homoskedasticity assumption (9a). Moreover, unless $\sigma_{b r}=0, \operatorname{cov}\left[b_{i}, \xi_{i} \mid Z_{i}=1\right] \neq \operatorname{cov}\left[b_{i}, \xi_{i} \mid Z_{i}=0\right]$. Thus, assumption (9b) is unlikely to hold.

Some evidence that changes in the institutional structure of the education system affect the mapping between ability and schooling outcomes is presented in Table I. This table reports the coefficients of an IQ measure from a series of descriptive regression models fit to the completed schooling of young men (age 14-24 in 1966) in the National Longitudinal Study. ${ }^{18}$ As shown in columns 1 and

\begin{tabular}{|c|c|c|c|c|c|c|}
\hline & \multicolumn{2}{|c|}{$\begin{array}{l}\text { Pooled } \\
\text { Sample }\end{array}$} & \multicolumn{2}{|c|}{$\begin{array}{l}\text { Near } \\
\text { College }\end{array}$} & \multicolumn{2}{|c|}{$\begin{array}{l}\text { Not Near } \\
\text { College }\end{array}$} \\
\hline & (1) & (2) & (3) & (4) & (5) & (6) \\
\hline Coefficient of IQ & $\begin{array}{c}0.075 \\
(0.003)\end{array}$ & $\begin{array}{c}0.068 \\
(0.003)\end{array}$ & $\begin{array}{c}0.081 \\
(0.003)\end{array}$ & $\begin{array}{c}0.072 \\
(0.004)\end{array}$ & $\begin{array}{c}0.059 \\
(0.005)\end{array}$ & $\begin{array}{c}0.058 \\
(0.006)\end{array}$ \\
\hline Other Controls & No & Yes & No & Yes & No & Yes \\
\hline$R$-squared & 0.260 & 0.348 & 0.249 & 0.375 & 0.175 & 0.299 \\
\hline $\begin{array}{l}\text { Number of } \\
\text { Observations }\end{array}$ & 2,061 & 2,061 & 1,460 & 1,460 & 601 & 601 \\
\hline
\end{tabular}
2 , IQ is a strong predictor of education, explaining about 25 percent of the variation in schooling outcomes among men in the sample. A one-standard

TABLE I

RELATIONSHIP BETWEEN IQ AND SCHOOLING

Note: Table reports coefficient of IQ in a linear regression model for completed education in 1976. Models in odd columns include no other controls. Models in even columns include both parents' education, age and age-squared, indicators for race, family structure at age 14, and region in 1966. Near College subgroup are those whose county of residence in 1966 had a local 4-year college (public or private). Sample includes men in the NLS Young Men sample who were interviewed in 1976 and who have valid education data for their parents and an IQ score obtained from their school records.

\footnotetext{
${ }^{18}$ Schooling is taken from the 1976 interview, when the men were $24-34$ years old. IQ measures were retrieved by NLS staff from the school records of men in the sample, and converted to a standardized basis (with mean 100 and standard deviation 15).
} 
deviation increase in IQ (e.g. from 95 to 110 ) is associated with 1.1 additional years of schooling when other background factors are ignored, and 1.0 added years of schooling when age, race, parental education, region of residence, and family structure at age 14 are all taken into account.

In the mid-1960s about 30 percent of the young men in the NLS sample lived in a county with no local 4-year college (either public or private). As noted in Card (1995), college proximity has a strong effect on completed education, even controlling for parental education, region, and IQ. Assuming that the presence of a nearby college is uncorrelated with ability (controlling for family background factors), college proximity is a potential instrumental variable for schooling. Even if ability is independent of college proximity, however, the remaining columns of Table I show that the correlation between education and ability (as measured by IQ) is different for men who grew up near a college and those who did not. Consistent with the idea that college proximity reduces the relative importance of cost factors in the schooling decision, the effect of IQ on completed education is significantly stronger among men who lived near a college than among those who did not. These results suggest that changes in the institutional structure of the education system can affect the mapping between individual ability and education outcomes, leading to a violation of assumptions such as independence or homoskedasticity needed for a conventional IV estimator to yield a consistent estimate of the average marginal return to education.

\section{Alternatives to IV}

A closely-related alternative to IV estimation of a random coefficients model is a control function approach, first proposed in the schooling context by Garen (1984) ${ }^{19}$ The basic idea of this approach is to make some assumptions about the nature of the covariances between the unobserved ability components $a_{i}$ and $b_{i}$ and the observable variables $S_{i}$ and $Z_{i}$, and include additional terms in the earnings model that capture these relationships. To illustrate, assume that all unobserved ability and taste components are mean-independent of $Z$. Assume further that the conditional expectations of the unobserved ability components $a_{i}$ and $b_{i}$ are linear in the schooling residual:

$$
E\left[\left(b_{i}-\bar{b}\right) \mid S_{i}, Z_{i}\right]=\psi_{0} \xi_{i}
$$

$$
E\left[a_{i} \mid S_{i}, Z_{i}\right]=\lambda_{0} \xi_{i}
$$

Equations (5), (9b), and (9c) imply that

$$
E\left[\log y_{i} \mid S_{i}, Z_{i}\right]=a_{0}+\bar{b} S_{i}-\frac{1}{2} k_{1} S_{i}^{2}+\lambda_{0} \xi_{i}+\psi_{0} \xi_{i} S_{i}
$$

\footnotetext{
${ }^{19}$ Willis and Rosen (1979) present a model with only two levels of education that includes both a random intercept in the earnings function and random earnings gain associated with the higher education choice. Their estimation procedure is essentially a control function approach.
} 
This equation can be estimated by a two-step procedure in which the estimated residual $\hat{\xi}_{i}$ from the reduced form schooling equation is substituted for $\xi_{i}$, and $\hat{\xi}_{i} S_{i}$ is substituted for $\xi_{i} S_{i}{ }^{20}$

To illustrate the connection between this approach and conventional IV, suppose that $k_{1}=0$. In this case it is well known that the inclusion of the reduced form residual $\hat{\xi}_{i}$ associated with the endogenous regressor $S_{i}$ leads to an OLS estimate of the coefficient on schooling that is identical to the one obtained by IV using $Z_{i}$ as an instrument for $S_{i}$. Under the assumption that $E\left[a_{i} \mid S_{i}, Z_{i}\right]=\lambda_{0} \xi_{i}$ the addition of $\hat{\xi}_{i}$ to the estimated earnings function purges the observed relationship between log earnings and schooling of any effect of $a_{i}{ }^{21}$ However, standard IV will not eliminate the influence of the heterogeneity component $\left(b_{i}-\bar{b}\right) S_{i}$ unless $E\left[\left(b_{i}-\bar{b}\right) S_{i} \mid Z_{i}\right]$ is orthogonal to $Z_{i}$ (as is the case if (9b) holds and $\xi_{i}$ is homoskedastic). Assuming that $E\left[\left(b_{i}-\bar{b}\right) \mid S_{i}, Z_{i}\right]$ is linear in the schooling residual $\xi_{i}$, however, the addition of $\hat{\xi}_{i} S_{i}$ as a second control variable is sufficient to eliminate endogeneity biases, even if the reduced form schooling residual is heteroskedastic.

In the case where changes in the instrumental variable affect the entire mapping between unobserved abilities and schooling outcomes, the assumption that $E\left[\left(b_{i}-\bar{b}\right) \mid S_{i}, Z_{i}\right]=\psi_{0} \xi_{i}$ is problematic, since $\operatorname{cov}\left[b_{i}, \xi_{1} \mid Z_{i}\right]$ potentially varies with $Z_{i}$, as does $\operatorname{var}\left[\xi_{i} \mid Z_{i}\right]$. Nevertheless, a simple extension of the control function approach may be appropriate if $Z_{i}$ is an indicator variable (as in the college proximity example). Specifically, replace (9b) and (9c) with

$$
\begin{array}{ll}
\left(9 \mathrm{~b}^{\prime}\right) & E\left[\left(b_{i}-\bar{b}\right) \mid S_{i}, Z_{i}\right]=\psi_{00}\left(1-Z_{i}\right) \xi_{i}+\psi_{01} Z_{i} \xi_{i}, \\
\left(9 \mathrm{c}^{\prime}\right) & E\left[a_{i} \mid S_{i}, Z_{i}\right]=\lambda_{00}\left(1-Z_{i}\right) \xi_{i}+\lambda_{01} Z_{i} \xi_{i} .
\end{array}
$$

According to $\left(9 \mathrm{~b}^{\prime}\right)$ and $\left(9 \mathrm{c}^{\prime}\right)$, the conditional expectations of the unobserved ability components are still linear functions of the schooling residuals within a particular institutional setting, but a change in the education system (from $Z_{i}=0$ to $\left.Z_{i}=1\right)$ is allowed to shift the relationship between schooling and ability. These assumptions imply that

$$
\begin{aligned}
E\left[\log y_{i} \mid S_{i}, Z_{i}\right]= & a_{0}+\bar{b} \cdot S_{i}-1 / 2 k_{1} S_{i}^{2}+\lambda_{00} \xi_{i}+\left(\lambda_{01}-\lambda_{00}\right) Z_{i} \xi_{i} \\
& +\psi_{00} S_{i} \xi_{i}+\left(\psi_{01}-\psi_{00}\right) Z_{i} S_{i} \xi_{i} .
\end{aligned}
$$

This model adds four control functions to the earnings model: the schooling residual, its interaction with $Z_{i}$, its interaction with $S_{i}$, and a three-way interaction with $S_{i} Z_{i}$.

A more radical alternative to IV is maximum likelihood estimation of a structural model of earnings and schooling, based on a complete specification of

${ }^{20}$ OLS estimation of the second step equation provides consistent coefficient estimates but the standard errors have to be adjusted for the first stage estimation error, as in Murphy and Topel (1985).

${ }^{21}$ In fact all that is needed is the assumption that the linear projection of $a_{i}$ on $\left(S_{i}, Z_{i}\right)$ is linear in $\xi_{i}$, which will be true under the standard orthogonality assumption $E\left[a_{i} Z_{i}\right]=0$. 
the unobservable components in the earnings function and the utility function. An advantage of this approach is that the earnings function can be made quite general-for example, by allowing the returns to different years of schooling to vary in a flexible manner with individual ability. Similarly, the choice function can be precisely specified, rather than approximated as in equation (3). Perhaps even more importantly, by fitting such a model to panel data it may be possible to recover information on the dynamic process by which individuals learn their abilities and modify their schooling choices over time, as in recent studies by Keane and Wolpin (1999) and Cameron and Taber (2000). This is a promising line of inquiry but is beyond the scope of this paper.

\section{What Does IV Estimate?}

If the returns to education vary across individuals and conditions such as those described earlier are not satisfied, what does a conventional instrumental variables estimator estimate? This question was addressed by Imbens and Angrist (1994) in the context of a dichotomous instrument that is independent of individual characteristics, and analyzed in more detail by Angrist and Imbens (1995), Angrist, Imbens, and Rubin (1996), and Angrist, Graddy, and Imbens (1995). To illustrate the key results, consider a schooling reform indexed by $Z_{i}$ that affects one of two otherwise identical populations. Suppose that a given individual would have schooling level $S_{i}^{C}$ and earnings $y_{i}^{C}$ if he or she attended the regular school system (i.e. if $Z_{i}=0$ ), whereas the same individual would have a schooling outcome $S_{i}^{C}+\Delta S_{i}$ if he or she attended a reformed school (i.e. if $\left.Z_{i}=1\right){ }^{22}$ Let $\beta_{i}$ denote individual $i$ 's marginal return to schooling. Ignoring second and higher-order terms, the effect of the schooling reform on earnings for individual $i$ is

$$
\Delta \log y_{i}=\beta_{i} \cdot \Delta S_{i} .
$$

The probability limit of an IV estimator of the return to schooling formed by pooling random samples from the $Z=0$ and $Z=1$ populations and using $Z_{i}$ as an instrument for schooling is

$$
\begin{aligned}
\operatorname{plim} b_{i v} & =\operatorname{cov}\left[\log y_{i}, Z_{i}\right] / \operatorname{cov}\left[S_{i}, Z_{i}\right] \\
& =\frac{E\left[\log y_{i} \mid Z_{i}=1\right]-E\left[\log y_{i} \mid Z_{i}=0\right]}{E\left[S_{i} \mid Z_{i}=1\right]-E\left[S_{i} \mid Z_{i}=0\right]}
\end{aligned}
$$

where expectations are taken over the joint distribution of the observable and unobservable characteristics in the two populations. By assumption, these distributions are the same, implying that $E\left[S_{i} \mid Z_{i}=1\right]=E\left[S_{i} \mid Z_{i}=0\right]+E\left[\Delta S_{i}\right]$, and

${ }^{22}$ The reduced form model for observed schooling is $S_{i}=\left(1-Z_{i}\right) S_{i}^{C}+Z_{i}\left(S_{i}^{C}+\Delta S_{i}\right)$. The random variable $\Delta S_{i}$ may be a function of underlying cost and ability parameters, as well as other factors. 
$E\left[\log y_{i} \mid Z_{i}=1\right]=E\left[\log y_{i} \mid Z_{i}=0\right]+E\left[\beta_{i} \cdot \Delta S_{i}\right]$. Therefore

$$
\operatorname{plim} b_{i v}=\frac{E\left[\beta_{i} \cdot \Delta S_{i}\right]}{E\left[\Delta S_{i}\right]} .
$$

Note that if $E\left[\beta_{i} \cdot \Delta S_{i}\right]=E\left[\beta_{i}\right] \cdot E\left[\Delta S_{i}\right]$, then the IV estimator provides a consistent estimate of the average marginal return to education $\bar{\beta}=E\left[\beta_{i}\right]$. This will be true if the schooling reform induces an equal change in schooling for all individuals, or more generally if $E\left[\Delta S_{i} \mid \beta_{i}\right]$ is independent of $\beta_{i}$. Otherwise, under the assumption that $\Delta S_{i} \geq 0$ for all $i$, the ratio on the right-hand side of equation (11) can be interpreted as a weighted average of the marginal returns to education in the population, where the "weight" for any particular "person" is the relative size of the increment in his or her schooling induced by the reform $\left(\Delta S_{i} / E\left[\Delta S_{i}\right]\right)$. Imbens and Angrist (1994) referred to this weighted average as the local average treatment effect (LATE). The bias in LATE relative to $\bar{\beta}$ depends on the covariance of $\beta_{i}$ and $\Delta S_{i}$. An IV procedure based on a school reform that leads to bigger changes in the education choices of people with relatively high marginal returns to education will tend to produce an over-estimate of the average marginal return to education.

In this light it is interesting to reconsider the effects of a supply-side change that causes a proportional reduction in the marginal cost of schooling, as described by equation (4"). In the unreformed school system, individual $i$ with ability parameter $b_{i}$ and cost parameter $r_{i}=\bar{r}+\eta_{i}$ obtains schooling $S_{i}=$ $\left(b_{i}-r_{i}\right) / k$, whereas the same individual in the reformed school system would obtain schooling $S_{i}=\left(b_{i}-\theta r_{i}\right) / k$. The induced change in schooling for individual $i$ is

$$
\Delta S_{i}=r_{i}(1-\theta) / k=\bar{r}(1-\theta) / k+\eta_{i}(1-\theta) / k,
$$

which is positive (assuming $r_{i} \geq 0$ ). Thus the monotonicity assumption needed for a LATE interpretation is satisfied. Individual $i$ 's marginal return to schooling in the absence of the intervention is

$$
\begin{aligned}
\beta_{i} & =b_{i}-k_{1} S_{i} \\
& =\bar{\beta}+\left(b_{i}-\bar{b}\right)\left(1-k_{1} / k\right)+\eta_{i} k_{1} / k .
\end{aligned}
$$

Substituting these expressions into equation (11), the probability limit of the IV estimator is

$$
\operatorname{plim} b_{i v}=\bar{\beta}+\left\{\sigma_{\eta}^{2} k_{1} / k+\sigma_{b \eta}\left(1-k_{1} / k\right)\right\} / \bar{r} .
$$

If individuals with higher returns to schooling have lower discount rates, then $\sigma_{b \eta} \leq 0$ and the IV estimator may be positively or negatively biased relative to $\bar{\beta} \cdot{ }^{23}$ A positive bias arises because the marginal return to schooling is decreasing

\footnotetext{
${ }^{23}$ If $\eta_{i}$ is the same for all $i$ (in which case everyone gets the same increment to schooling), then $\sigma_{\eta}^{2}=\sigma_{b \eta}=0$, and the IV estimator is consistent for $\bar{\beta}$. Alternatively, if earnings are linear in schooling $\left(k_{1}=0\right)$ and $\sigma_{b \eta}=0$ the estimator is also consistent. The latter assumptions satisfy the second version of Wooldridge's (1997) conditions, described in footnote 17.
} 
in education if $k_{1}>0$ : thus people with initially higher marginal costs of schooling (who are more affected by the cost reduction) tend to have higher marginal returns to an additional year of schooling. Lang (1993) labeled this phenomenon "discount rate bias." ${ }^{24}$ On the other hand, a negative bias arises because people with higher marginal costs of education also tend to have lower marginal returns to schooling if $\sigma_{b \eta}<0$. The positive bias is more likely to dominate, the smaller is $\left|\sigma_{b \eta}\right|$ relative to $\sigma_{\eta}^{2}$ and the more concave are individual earnings functions.

Two other features of an instrumental variables estimator of the return to schooling are worth emphasizing. First, the probability limit of the IV estimator is unaffected by classical measurement error in schooling. ${ }^{25}$ This in itself will lead to a tendency for an IV estimator to exceed the corresponding OLS estimator of the return to schooling. Second, the validity of a particular IV estimator depends crucially on the assumption that the instruments are uncorrelated with other latent characteristics of individuals that may affect their earnings. In the case of an IV estimator based on an indicator variable $Z_{i}$, for example, the IV estimator is numerically equal to the difference in mean log earnings between the $Z_{i}=1$ group and the $Z_{i}=0$ group, divided by the corresponding difference in mean schooling. ${ }^{26}$ If the difference in schooling is small, even minor differences in mean earnings between the two groups will be blown up by the IV procedure. If $Z_{i}$ were randomly assigned, as in a true experiment, this would not be a particular problem. In observational studies, however, inferences are based on differences between groups of individuals who attended schools at different times, or in different locations, or had differences in other characteristics such as month of birth. The use of these differences to draw causal inferences about the effect of schooling requires careful consideration of the maintained assumption that the groups are otherwise identical.

To illustrate the issues, consider an analysis of education and earnings for individuals in a specific cohort, relative to those in other surrounding cohorts (as in Ichino and Winter-Ebmer (1998), or Lemieux and Card (1998), described below). Assume that the reduced form schooling model for individual $i$ in cohort $c$ is

$$
S_{i c}=\pi_{0}+Z_{i c} \pi_{1}+\xi_{i c},
$$

where $Z_{i c}=1$ if $i$ is a member of cohort $T$, and 0 otherwise, and $\xi_{i c}=(1-$ $\left.Z_{i c}\right) \xi_{i 0 c}+Z_{i c} \xi_{i 1 c}$. The incremental gain in education associated with member-

${ }^{24}$ As the model in Section I makes clear, variation in the marginal cost of schooling may reflect tastes for schooling versus work, as well as differences in discount rates. The term "discount rate bias" may convey an overly restrictive interpretation of the underlying phenomenon.

${ }^{25}$ This assumes that the instrumental variable is uncorrelated with the measurement error in schooling. Kane, Rouse, and Staiger (1999) note that if the measurement errors in schooling are larger, or more systematically correlated with true schooling for a subset of observations that receives more weight in the LATE formula, then IV may be biased.

${ }^{26}$ If other covariates are included in the model, then the means for each subsample are adjusted for the effects of the covariates. 
ship in the affected cohort (relative to the comparison cohorts) is $\Delta S_{i c}=\pi_{1}+$ $\xi_{i 1 c}-\xi_{i 1 c}$. Assume that the earnings function is

$$
\log y_{i c}=a_{0}+\beta_{i} S_{i c}+a_{i c}+e_{i c}
$$

where $e_{i c}$ is an error component capturing determinants of earnings other than ability or education. Suppose that individuals in different cohorts have the same distributions of ability and tastes, so that

$$
E\left[a_{0}+\beta_{i} S_{i c}+a_{i c} \mid c=T\right]=E\left[a_{0}+\beta_{i} S_{i c}+a_{i c} \mid c \neq T\right]+E\left[\beta_{i} \Delta S_{i c}\right] .
$$

Finally, assume that $e_{i c}=e_{c}+\epsilon_{i c}$ where $e_{c}$ is a random effect representing the influence of unobserved factors that are common across individuals in the same cohort. ${ }^{27}$ In this case, an IV estimator based on membership in cohort $T$ has

$$
\operatorname{plim} b_{i v}=\frac{E\left[\beta_{i} \cdot \Delta S_{i}\right]+e_{T}-\operatorname{Average}\left(e_{c} \mid c \neq T\right)}{E\left[\Delta S_{i}\right]},
$$

where Average $\left(e_{c} \mid c \neq T\right)$ represents a weighted average of the cohort effects for the comparison cohorts. ${ }^{28}$ Although one can think of $e_{c}$ as a random variable that averages to 0 across many cohorts, the IV estimator is based on the gap in earnings between a particular cohort $T$ and a fixed set of comparison cohorts. To the extent that $e_{T}$ is a "bad draw," or the average of the cohort effects in the comparison sample is far from 0, the IV estimator may give a misleading estimate of the return to education. Moreover, the conventional sampling error of the IV estimator makes no allowance for any inherent uncertainty associated with the variance of $e_{c}$.

These considerations suggest that an IV procedure that implicitly compares many subgroups of individuals - say, younger versus older cohorts in several different regions - may be more reliable than one that relies on a single affected subgroup. They also illustrate the importance of identifying interventions or changes on the supply side of the education market that generate large changes in schooling, since the bias associated with a particular realization of the cohort effects is $\left\{e_{T}-\right.$ Average $\left.\left(e_{c} \mid c \neq T\right)\right\} / \Delta \bar{S}$, where $\Delta \bar{S}$ is the difference in mean schooling between the affected cohort and the comparison cohorts. If an estimate of $\sigma_{c}$ (the standard deviation of $e_{c}$ ) is available, it may be useful to make an assessment of the potential magnitude of any biases associated with a "bad draw" on $e_{T}$ by comparing the magnitudes of $b_{i v}$ to $\sigma_{c} / \Delta \bar{S}$. If $\sigma_{c} /|\Delta \bar{S}|$ is large relative to $\left|b_{i v}\right|$, a cross-cohort comparison is not a particularly attractive basis for inferring the causal effect of schooling.

\footnotetext{
${ }^{27} \mathrm{An}$ example of such a factor is the state of the business cycle at the beginning of the cohort's labor market career, which may exert a permanent effect on the cohort's earnings (see Beaudry and DiNardo (1991)).

${ }^{28}$ The weights are the relative fractions of the comparison sample from each of the comparison cohorts, which are assumed to be fixed as the sample size grows.
} 


\section{INSTRUMENTAL VARIABLES ESTIMATES OF THE RETURN TO} SCHOOLING

I now turn to a selective review of recent studies that have used institutional features of the schooling system to identify the return to schooling. ${ }^{29}$ Table II summarizes eleven recent studies that estimate the return to schooling using instrumental variables based on this idea. For each study I report both OLS and IV estimates derived from the same sample with the same control variables.

The first entry in the table is Angrist and Krueger's (1991) landmark study of compulsory schooling and education, which uses an individual's quarter of birth (interacted with year of birth or state of birth in some specifications) as an instrument for schooling. Angrist and Krueger observed that U.S. men born from 1930 to 1959 with birth dates earlier in the year have slightly less schooling then men born later in the year - an effect they attribute to compulsory schooling laws. Specifically, they note that children born in the same calendar year generally start school at the same time (e.g. in September of the year they turn 6). As a result of this institutional feature, individuals born earlier in the year reach the minimum school-leaving age at a lower grade than people born later in the year, allowing those who want to drop out as soon as legally possible to leave school with less education. Assuming that quarter of birth is independent of taste and ability factors, this phenomenon generates exogenous variation in education that can be used in an IV estimation scheme.

Angrist and Kreuger's empirical analysis confirms that the quarterly pattern in school attainment is paralleled by a similar pattern in earnings. As shown in Table II, their IV estimates of the return to education are typically higher than the corresponding OLS estimates, although for some cohorts and specifications the two estimators are very close, and in no case is the difference between the IV and OLS estimators statistically significant.

Angrist and Krueger's findings have attracted much interest and some criticism. Bound, Jaeger, and Baker (1995) pointed out that several of Angrist and Krueger's IV models (specifically, those that use interactions between quarter of birth and state of birth as predictors for education) include large numbers of weak instruments, and are therefore asymptotically biased toward the corresponding OLS estimates. This "weak instruments" bias is not as serious for the specifications reported in Table II, which rely on a more parsimonious set of instruments. Moreover, to the extent that Angrist and Krueger's IV estimates are above the corresponding OLS estimates, one might infer that asymptotically unbiased estimates of the causal effect of education are even higher. This is confirmed by the findings of Staiger and Stock (1997), who re-analyzed the 1980 Census samples used by Angrist and Krueger and computed a variety of asymptotically valid confidence intervals for standard IV and limited informa-

\footnotetext{
${ }^{29}$ The idea of using institutional features of the school system to overcome problems of endogeneity and unobserved ability is also proving useful in studies of the effect of school quality. For example, Angrist and Lavy (1999) use information on legally-mandated maximum class sizes to identify the effect of class size on student achievement.
} 


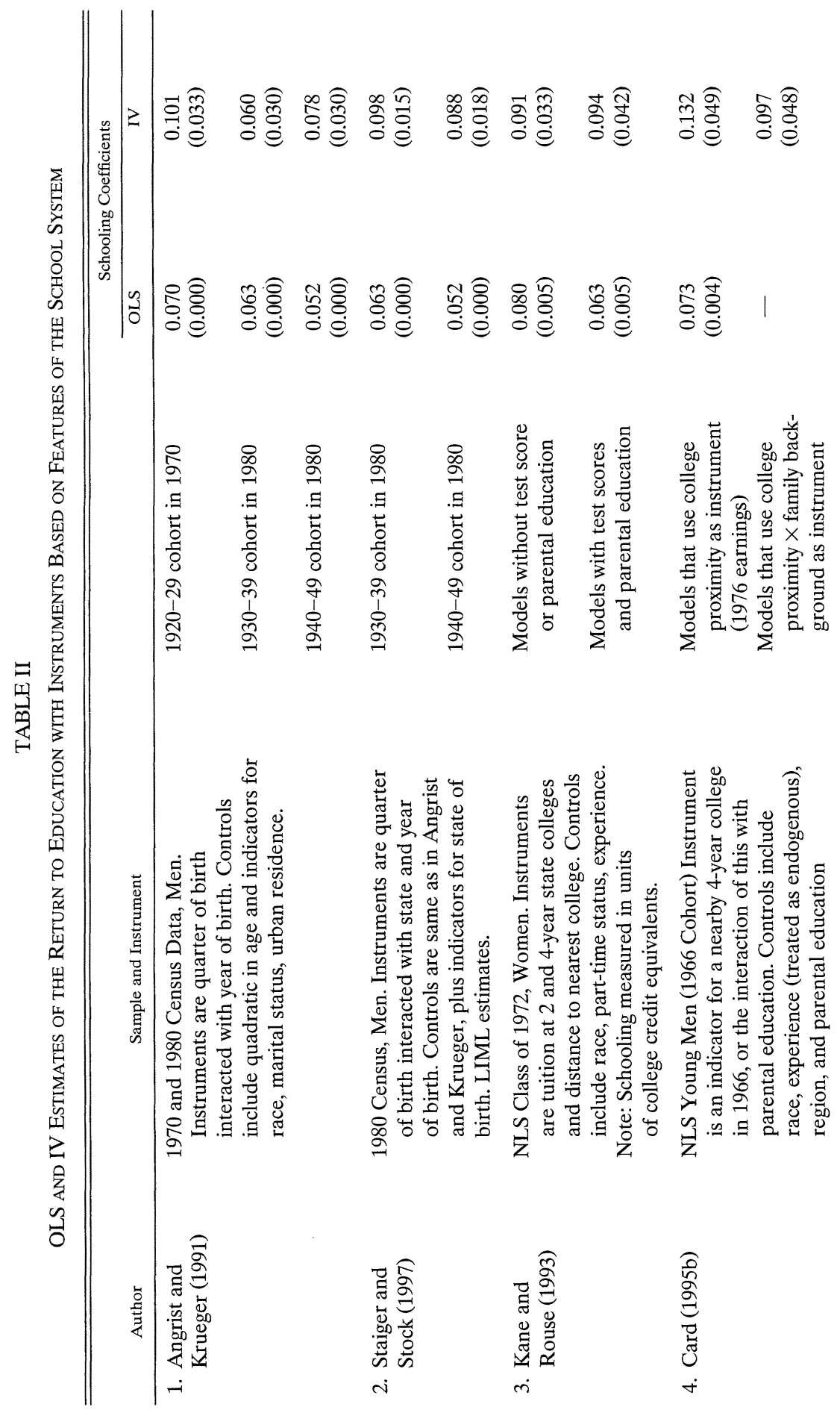




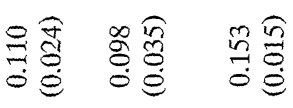

कลิ

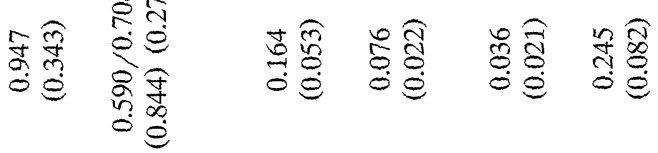

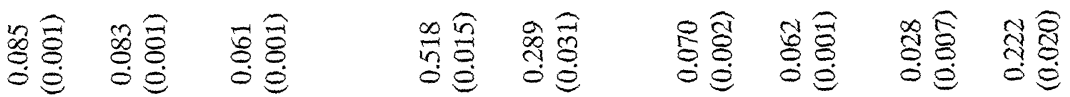

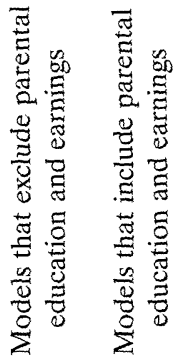

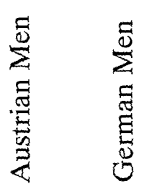

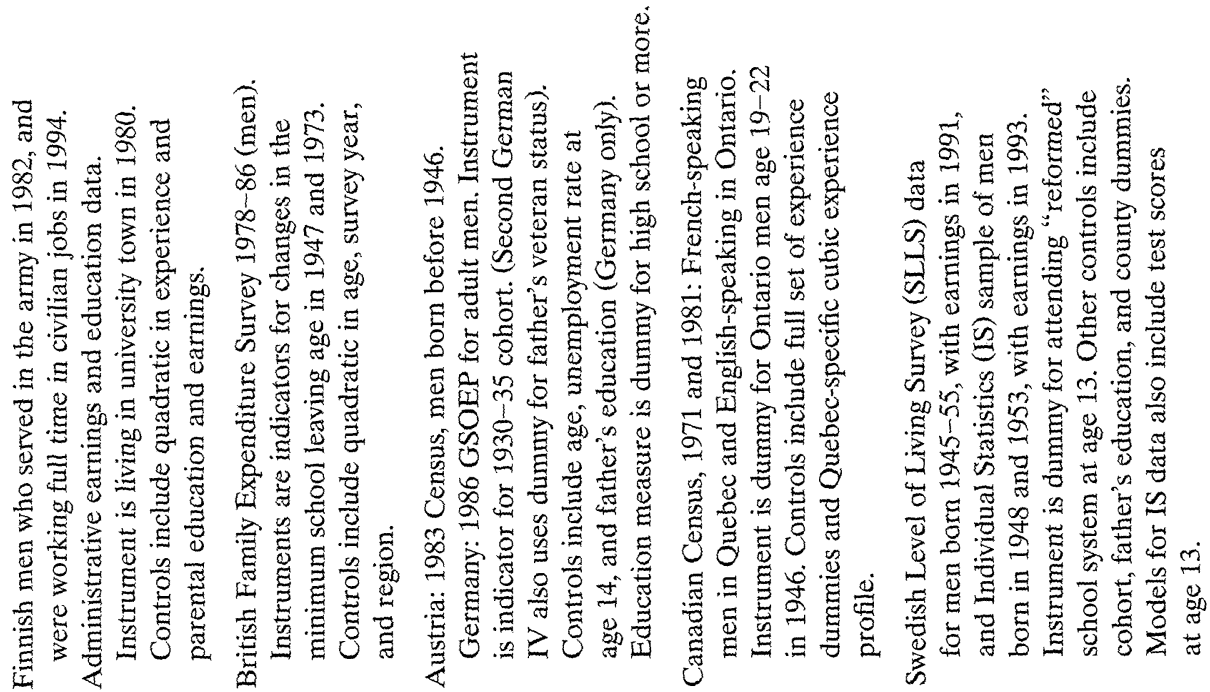

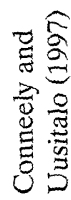

in

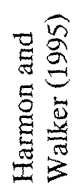

6

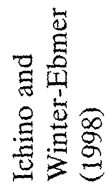

$\dot{r}$

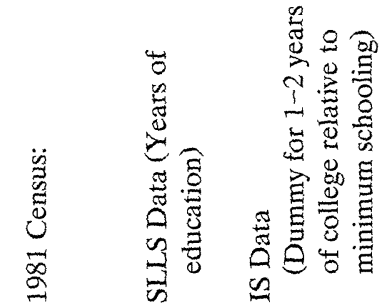

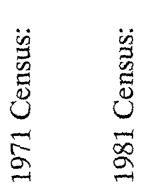


TABLE II-Continued

\begin{tabular}{|c|c|c|c|c|}
\hline \multirow[b]{2}{*}{ Author } & \multirow[b]{2}{*}{ Sample and Instrument } & & \multicolumn{2}{|c|}{ Schooling Coefficients } \\
\hline & & & OLS & IV \\
\hline 10. Maluccio (1997) & $\begin{array}{l}\text { Bicol Multipurpose Survey (rural Philippines): } \\
\text { male and female wage earners age } 20-44 \text { in } \\
\text { 1994, whose families were interviewed in } 1978 . \\
\text { Instruments are distance to nearest high } \\
\text { school and indicator for local private high } \\
\text { school. Controls include quadratic in age and } \\
\text { indicators for gender and residence in a } \\
\text { rural community. }\end{array}$ & $\begin{array}{l}\text { Models that do not control for } \\
\text { selection of employment } \\
\text { status or location } \\
\text { Models with selection } \\
\text { correction for location } \\
\text { and employment status }\end{array}$ & $\begin{array}{c}0.073 \\
(0.011) \\
\\
0.063 \\
(0.006)\end{array}$ & $\begin{array}{c}0.145 \\
(0.041)\end{array}$ \\
\hline 11. Duflo (1999) & $\begin{array}{l}1995 \text { Intercensal Survey of Indonesia: men born } \\
\text { 1950-72. Instruments are interactions of birth } \\
\text { year and targeted level of school building } \\
\text { activity in region of birth. Other controls are } \\
\text { dummies for year and region of birth and } \\
\text { interactions of year of birth and child } \\
\text { population in region of birth. Second IV } \\
\text { adds controls for year of birth interacted } \\
\text { with regional enrollment rate and presence } \\
\text { of water and sanitation programs in region. }\end{array}$ & $\begin{array}{l}\text { Model for monthly wage with } \\
\text { imputation for self-employed. }\end{array}$ & $\begin{array}{c}0.078 \\
(0.001)\end{array}$ & $\begin{array}{c}0.064 / 0.091 \\
(0.025)(0.023) \\
\\
0.064 / 0.049 \\
(0.017)(0.013)\end{array}$ \\
\hline
\end{tabular}

Notes: See text for sources and more information on individual studies. 
tion maximum likelihood (LIML) estimates. Staiger and Stock's preferred LIML estimates, utilizing quarter of birth interacted with state of birth and year of birth as instruments, are reported in row 2 of Table II. These are uniformly above the corresponding two-stage least squares estimates, and 50-70 percent higher than the OLS estimates.

A second criticism of Angrist and Krueger's findings, raised by Bound and Jaeger (1996), is that quarter of birth may be correlated with unobserved ability differences. Bound and Jaeger examine the schooling outcomes of earlier cohorts of men who were not subject to compulsory schooling institutions and find some evidence of seasonal patterns. They also discuss evidence from the sociobiology and psychobiology literature that suggests that season of birth is related to family background. To the extent that children born earlier in the year have poorer family backgrounds, one might expect them to have lower completed education and lower earnings. Moreover, if the quarterly patterns of education and earnings are solely attributable to differences in family background, then Angrist and Krueger's IV estimators have the same bias as IV estimators based directly on family background. ${ }^{30}$ Although the Census data used by Angrist and Krueger contain no information on family background, it is possible to use other data sources to examine differences in family background by quarter of birth for similar cohorts. For example, I used 1940 Census data to compare the mean levels of parental education by quarter of birth for children under one year of age. ${ }^{31}$ The mean levels of mother's education for these children are 9.04, 8.95, 8.97, and 8.95 for quarters I-IV, respectively (with standard errors of about 0.05 ). The corresponding means of father's education are $8.61,8.50,8.52$, and 8.58. These comparisons give no indication that children born in the first quarter come from relatively disadvantaged family backgrounds, and suggest that the seasonal patterns identified by Angrist and Krueger are not simply attributable to differences in family background.

The third study summarized in Table II, by Kane and Rouse (1993), is primarily concerned with the relative labor market valuation of credits from regular (4-year) and junior (2-year) colleges. Their findings suggest that credits awarded by the two types of colleges are interchangeable: in light of this conclusion they measure schooling in terms of total college credit equivalents. In analyzing the earnings effects of college credits, Kane and Rouse compare OLS specifications against IV models that use the distance to the nearest 2-year and 4-year colleges and state-specific tuition rates as instruments. Their IV estimates based on these instruments are $15-50 \%$ above the corresponding OLS specifications.

\footnotetext{
${ }^{30}$ As noted in Card (1999), IV estimators of the return to schooling using parental education as an instrument tend to be substantially above the corresponding OLS estimators.

${ }^{31}$ The 1940 Census, which was conducted in April, reports month of birth for children under one year of age. There are 19,089 children under 1 year of age in the public use file, of whom 98.4 percent can be matched to a female head of household and 95.3 percent can be matched to a male head of household.
} 
Two subsequent studies by Card (1995) and Conneely and Uusitalo (1997) examine the schooling and earnings differentials associated with growing up near a college or university. In my 1995 study I found that when college proximity is used as an instrument for schooling in the National Longitudinal Survey (NLS) Young Men sample, the resulting IV estimator is substantially above the corresponding OLS estimator, although rather imprecise. Consistent with the idea that accessibility matters more for individuals on the margin of continuing their education, college proximity is found to have a bigger effect for children of less-educated parents. ${ }^{32}$ This suggests an alternative specification that uses interactions of college proximity with family background variables as instruments for schooling, and includes college proximity as a direct control variable. The IV estimate from this interacted specification is somewhat lower than the estimate using college proximity alone, but still about 30 percent above the OLS estimate.

The Conneely-Uusitalo (1997) study utilizes a very rich Finnish data set that combines family background information, military test scores, and administrative earnings data for men who served in the army in 1982. Like Kane and Rouse (1993) and Card (1995) they find that IV estimates of the return to schooling based on college proximity exceed the corresponding OLS estimates by 20-30 percent, depending on what other controls are added to the model. It is worth noting that all three of these studies report models that control for a fairly detailed set of family background characteristics. Such controls are desirable if families that live near colleges have different family backgrounds, and if family background has some independent causal effect on earnings. Conneely and Uusitalo's IV estimate controlling for parental education and earnings is below the IV estimate that excludes these controls, but is still above the simplest OLS estimate without family background controls. Despite the rather large size of their sample (about 22,000 observations) and the very high quality of their underlying data, however, Conneely and Uusitalo's IV estimates are somewhat imprecise, and are not significantly different from their OLS estimates. ${ }^{33}$

The next group of four studies in Table II uses cohort differences as a source of identification of the return to schooling. Harmon and Walker (1995) study the returns to education among British male household heads using changes in the legal minimum school-leaving age as instruments for completed education. Their instruments distinguish between three cohorts of men: those born before 1932, who faced a minimum school-leaving age of 14; those born from 1933 to 1957, who faced a minimum age of 15; and those born after 1957, who faced a minimum age of 16 . As shown in Table II the IV estimate based on these cohort dummies is considerably above the corresponding OLS estimate (2.5 times

\footnotetext{
${ }^{32}$ Kling (1999) re-analyses the same data and reports similar findings, including significant differences in the distribution of schooling attainment between those near and far from college in the lowest quartiles of family background.

${ }^{33}$ Conneely and Uusitalo also implement a more general control function estimator, as described above.
} 
higher) and is relatively precise. Several features of their estimation strategy suggest the need for caution in the interpretation of these findings, however. Most importantly, the 1947 law change - which is the major source of identification in their results - came just after World War II and may capture other cohort differences between those who attended school before, during, and after WWII. ${ }^{34}$ Moreover, Harmon and Walker do not allow for systematic inter-cohort growth in educational attainment, other than that attributable to the law changes in 1974 and $1973 .{ }^{35}$ Both these factors may affect their IV estimators, which pool many cohorts of men, rather than relying on comparisons between cohorts who attended school just before and just after the law changes.

The seventh study in Table II, by Ichino and Winter-Ebmer (1998), focuses on the disruptive effects of World War II on the schooling of children in Austria and Germany born between 1930 and 1935. They argue that WWII had a particularly strong effect on the educational attainment of children who reached their early teens during the war and lived in countries directly subject to hostilities. Using data for 14 countries they find relatively big differences in completed education for children in the 1930-35 cohort in countries that were most heavily affected by the war (e.g. Germany, Austria, and the U.K.) but relatively small differences for this cohort in other places (e.g. the U.S. and Ireland). When they use an indicator for the 1930-35 cohort as an instrument for schooling (measured by a single dummy variable indicating more than a minimal level of schooling) they find that the earnings advantage roughly doubles from its OLS value in both Austria and Germany, although the IV estimates are imprecise. While one might be concerned that the 1930-35 cohort suffered other disadvantages besides their disrupted education careers, these results are comparable to Harmon and Walker's (1995) in terms of the magnitude of the IV/OLS gap. For their German sample Ichino and Winter-Ebmer also consider a second IV estimator that uses cohort and father's veteran status as instruments. The resulting estimate is slightly larger and substantially more precise than the one based on cohort alone.

Study number 8 in Table II, by Lemieux and Card (1998), also uses a cohort-specific difference in educational attainment attributable to WWII. In this case, the differential is associated with educational benefits offered to Canadian veterans. ${ }^{36}$ Lemieux and Card note that the fraction of veterans was much higher among English-speaking Canadians than French-speaking Canadians. Moreover, after the war, French-speaking colleges in Quebec made few

\footnotetext{
${ }^{34}$ As noted below, Ichino and Winter-Ebmer (1998) find that the educational attainments of children born between 1930 and 1935 were substantially below those of children born just earlier or later in many European countries.

${ }^{35}$ Their specifications control for age and survey year. One can infer the presence of important cohort effects from the fact that their survey year effects show a 0.5 year rise in educational attainment between surveys in 1979 and 1986, controlling for age and the school-leaving age indicators.

${ }^{36} \mathrm{~A}$ similar package of education benefits-known as the G.I. Bill—was available to U.S. veterans, and is credited with fundamentally changing U.S. higher education.
} 
changes to accommodate returning veterans, whereas universities in the rest of Canada set up transitional programs that allowed many veterans-including those who had not finished high school-to enter college. This combination of factors meant that veteran education benefits had little or no effect on Frenchspeaking Canadians, but a potentially large effect among English-speakers. In view of the difference, Lemieux and Card use the interaction of English-speaking ethnicity with a cohort effect for men who were age 19-22 in 1946 as an instrument for education. The advantage of this strategy is that it allows for arbitrary cohort effects in observed earnings and educational attainment, and relies on differences between English and French speakers in one cohort relative to others to identify the return to education. Instrumental variables estimates based on this strategy are $20-100$ percent above the corresponding OLS estimates of the return to education, with the more precise estimates nearer the bottom of this range.

The fourth cohort-based study, by Meghir and Palme (1999), examines education and earnings outcomes of Swedish men born in the late 1940's and early 1950's who were affected by the introduction of a new education system that raised the minimum years of schooling by 2 and instituted other changes. The new system was introduced on a municipality-by-municipality basis over the 1950-62 period. By 1961 about one-half of municipalities were operating under the new system and in 1962 the system was implemented nationally. Meghir and Palme use a simple dummy variable indicating whether an individual attended a reformed school system as an instrument for schooling. Their reduced-form models suggest that average years of schooling are about 0.8 years higher for men who attended the reformed schools than for those who did not, controlling for year of birth, father's education, and county of residence.

To evaluate the earnings impacts of this extra education Meghir and Palme use two samples: a small sample of men born from 1945 to 1955 and interviewed in the 1991 Swedish Level of Living Survey (SLLS); and a larger sample of men born in 1948 and 1953 and included in the Individual Statistics (IS) data set. Both surveys are linked to administrative earnings records and therefore provide relatively precise earnings data. The IS data set also includes a battery of test information obtained on individuals at age 12-13. Using the SLLS data set, they obtain an OLS estimate of 0.028 for the return to schooling, and a corresponding IV estimate of 0.036 , although the latter is relatively imprecise. ${ }^{37}$ Meghir and Palme's results for the IS sample are derived from a model that includes dummy variables for each of 6 education levels. Only the first 4 of these dummies are treated as endogenous in their IV specifications, via the inclusion of generalized residuals from an ordered probit model of schooling. ${ }^{38}$ I summarize their results by reporting the OLS and IV estimates of the earnings premium for the highest education level that is treated as endogenous. As in the

\footnotetext{
${ }^{37}$ They also report a control function estimate from a model that includes the reduced form schooling residual interacted with schooling. This estimate is very similar to the IV estimate.

${ }^{38}$ A similar specification was implemented by Garen (1984).
} 
simpler linear models from the SLLS sample, the IV estimate from this specification is slightly above the corresponding OLS estimate, although the OLS/IV difference is not significant.

The final two studies in Table II are both based on data for developing economies. Study number 10, by Maluccio (1997), applies the school proximity idea to data from the rural Philippines. Maluccio combines education and earnings information for a sample of young adults with data for their parents' households, including the distance to the nearest high school and an indicator for the presence of a local private high school. These variables have a relatively strong effect on completed education in this sample. Maluccio estimates OLS and conventional IV models using school proximity as an instrument, as well as IV models that include a selectivity correction for employment status and location. Both IV estimates are substantially above the corresponding OLS estimates. Maluccio's analysis suggests that the reliability of his schooling variable is somewhat lower than in conventional U.S. or European data sets, accounting for some of the gap between the IV and OLS estimates. Maluccio does not present OLS or IV models that control for family background. Rather, he presents IV models that use parental education and wealth as additional instruments for education, leading to slightly smaller but somewhat more precise IV estimates.

The final study in Table II, by DuFlo (1998), examines the education and earnings trends associated with a school building program in Indonesia in the 1970 's. The program set a target number of primary schools to be built in each of Indonesia's 281 districts, based on the enrollment rate of primary-school age children in the district in 1972. DuFlo shows that average educational attainments rose more quickly in districts that had a greater program intensity, measured by the target number of new schools per primary-school age student in the district in 1971. She also argues that the program had a bigger effect (on average) for children who entered school later in the 1970's, and no effect for children who finished primary school before 1974. Based on these considerations she uses interactions of year of birth with program intensity in the district of birth as instruments for schooling. Her samples include individuals age 2-24 in 1974: those who were age 13-24 are presumed to have been unaffected by the school building program (and are therefore assigned a 0 value for the program intensity variable). The presence of these "unaffected" individuals in each district allows her to include unrestricted district-specific fixed effects in the earnings models.

DuFlo's basic OLS and IV models are fit to a sample of wage-earners (as of 1991). The OLS estimate of the return to schooling using hourly wages of this sample is 0.078 , while the IV estimate is slightly smaller -0.064 percent. The magnitude of the OLS estimate is unaffected by the addition of controls for region-specific enrollment rates prior to the school-building program and measures of spending on region-specific water and sanitation programs. The addition of these controls to the IV models, however, leads to a slightly larger and slightly more precise estimate, as shown by the second entry reported in the IV 
column of Table II. DuFlo also reports results based on monthly earnings, with imputed values for self-employed workers. In these specifications the estimated returns to schooling are somewhat lower: the OLS estimate is 0.057 , the IV estimate without added controls is 0.064 , and the IV estimate with controls for district-level enrollment rates before the school-building program and districtlevel water and sanitation programs is 0.049 . As in many of the other studies summarized in Table II, none of the IV estimates is significantly different from the corresponding OLS estimate.

In addition to the 11 studies included in Table II, a few other relatively recent studies have used IV techniques to estimate the return to schooling. One innovative example is Hausman and Taylor (1981), which used the means of three time-varying covariates (age and indicators for the incidence of bad health and unemployment) as instruments for education in a panel data model of earnings outcomes for prime-age men. Hausman and Taylor find that the return to schooling rises from about 7 percent in OLS specifications to 12-13 percent in their IV specifications. Although subsequent researchers have not directly followed Hausman and Taylor's methodology, their use of mean age as an instrument for schooling is equivalent to using a linear cohort variable, and is thus similar in spirit to several of the studies in Table II.

Another pair of studies not reported in Table II, by Angrist and Krueger (1992, 1995), examines the effect of "draft avoidance" behavior on the education and earnings of men who were at high risk of being drafted under the lottery system used during the Viet Nam war. During one phase of the draft, enrolled students could obtain draft exemptions, and many observers have argued that draft avoidance led to higher college enrollment rates among men with the highest probabilities of being drafted. If this was true, one could use draft lottery numbers - which were randomly assigned by day of birth-as instruments for education. While Angrist and Krueger (1992) reported initial IV estimates based on this idea, subsequent research (Angrist and Krueger (1995)) showed that the link between lottery numbers and completed education is quite weak. In fact, the differences in education across groups of men with different lottery numbers are not statistically significant, suggesting that draft avoidance by those with low lottery numbers had a negligible effect on their schooling behavior. ${ }^{39}$

A third pair of recent papers not included in Table II are studies of the returns to education in Ireland and Italy by Callan and Harmon (1999) and Brunello and Miniaci (1999). Both of these papers describe institutional changes in the education systems of the two countries that potentially affected the schooling attainments of more recent cohorts. In each case, however, the "school reform" instrument is combined with other instruments based on parental education and/or socioeconomic class. Callan and Harmon report that

\footnotetext{
${ }^{39}$ The conventional IV estimates are typically equal to or just above the OLS estimates. Angrist and Krueger (1995) propose a "split sample" IV method to deal with the weak instruments problem. The split-sample IV estimates are all very imprecise.
} 
the Irish schooling reform variables (which capture changes in the school-leaving age and the introduction of free secondary education) have no significant effect on schooling attainment. Thus, the schooling reform variables by themselves are not useful instruments for education, and Callan and Harmon's IV estimates are driven by their family background instruments. Brunello and Miniaci do not report a comparable test of the effects of the Italian reforms. Nevertheless, an examination of inter-cohort trends in their data set suggests that the education reform they discuss (a 1969 law that opened universities to all students regardless of high school curriculum) had little discontinuous effect on educational attainment. ${ }^{40}$ Even if the reform had some effect, it is likely to be "overpowered" in the reduced form models by the effects of parental education. In light of the potential correlations between family background and ability differences, IV estimators based on family background do not shed much light on the magnitude of any ability or endogeneity biases in the return to education (see Card (1999) for an extended discussion).

\section{Interpretation}

An interesting finding that emerges from the studies in Table II is that instrumental variables estimates of the return to schooling typically exceed the corresponding OLS estimates - often by 20 percent or more. If one assumes on a priori grounds that OLS methods lead to upward-biased estimates of the true causal effect of schooling, the even larger IV estimates obtained in many recent studies present something of a puzzle. A number of explanations have been offered for this pattern. The first explanation-proposed by Griliches (1977) and echoed by Angrist and Krueger (1991) - is that ability biases in the OLS estimates of the return to schooling are relatively small, and that the gaps between the IV and OLS estimates in Table II reflect the downward bias in the OLS estimates attributable to measurement errors. The imprecision of most of the IV estimates in Table II makes it difficult to rule out this explanation on a study-by-study basis. Since measurement error bias by itself can only explain a 10 percent gap between OLS and IV, however, it seems unlikely that so many studies would find large positive gaps between their IV and OLS estimates simply because of measurement error. ${ }^{41}$

A second explanation is that the IV estimates are even further upward biased than the corresponding OLS estimates by unobserved differences between the characteristics of the "treatment" and "comparison" groups implicit in the IV scheme. A two-stage least squares estimator based on a quasi-experimental comparison can be interpreted as an estimate of the return to schooling using grouped data, where there are only two groups. As in other situations where a

\footnotetext{
${ }^{40} \mathrm{I}$ am grateful to Marco Manacorda for his analysis of the Bank of Italy survey data.

${ }^{41}$ One caveat to this conclusion is the possibility that measurement errors are larger, or more systematically correlated with schooling levels, for individuals most affected by the interventions underlying the analyses in Table II. Kane, Rouse, and Staiger (1999) find some evidence of this.
} 
micro-level regression model is compared to a grouped regression, grouping may accentuate any inherent biases in the micro-level model by reducing the variance in the independent variable (schooling) by more than it reduces the covariance of the independent variable with the bias terms. ${ }^{42}$ This possibility can never be ruled out on a priori grounds, and may be especially worrisome for quasi-experimental comparisons based on treatment and comparison groups that differ in terms of family background or measured ability. The only remedy (short of conducting randomized experiments) is to compare the results from a wide variety of different "quasi-experiments," and to ensure that observable differences between the treatment and comparison group are taken into consideration whenever possible.

A third possibility, suggested in a recent overview of the returns to education literature by Ashenfelter, Harmon, and Oosterbeek (1999), is "specification searching." They hypothesize that in comparing alternative IV specifications, researchers tend to favor those that yield a higher $t$ statistic for the estimated return to schooling. If minor changes in specification have little effect on the precision of the IV estimator, but generate a range of point estimates, this behavior will lead to a positive bias in the distribution of reported IV estimates, and to a positive correlation across reported specifications between the IV-OLS gap and the sampling error of the IV estimate. Ashenfelter, Harmon, and Oosterbeek find such a positive correlation, and conclude that there may be some specification search bias in the literature. ${ }^{43}$

A final explanation is that there is underlying heterogeneity in the returns to education, and that many of the IV estimates based on supply-side innovations tend to recover returns to education for a subset of individuals with relatively high returns to education. Institutional features like compulsory schooling or the accessibility of schools are most likely to affect the schooling choices of individuals who would otherwise have relatively low schooling. If the main reason that these individuals have low schooling is because of higher-than-average costs of schooling, rather than because of lower-than-average returns to schooling, then "local average treatment effect" reasoning suggests that IV estimators based on compulsory schooling or school proximity will yield estimated returns to schooling above the average marginal return to schooling in the population, and potentially above the corresponding OLS estimates. Under this scenario, both the OLS and IV estimates are likely to be upward-biased

\footnotetext{
${ }^{42}$ Consider a model for individuals who belong to groups (indexed by $j$ ): $y_{i j}=a+b x_{i j}+e_{i j}$. The asymptotic bias in the micro-level OLS regression coefficient is $\operatorname{cov}\left[x_{i j}, e_{i j}\right] / \operatorname{var}\left[x_{i j}\right]$. If the model is fit by weighted OLS to grouped data, the corresponding bias is $\operatorname{cov}\left[x_{j}, e_{j}\right] / \operatorname{var}\left[x_{j}\right]$, where $x_{j}$ denotes the mean of $x_{i j}$ in group $j$, and $e_{j}$ is the mean residual in group $j$. The ecological fallacy problem arises because although $\operatorname{var}\left[e_{j}\right]$ may be small, the bias in the grouped data regression may be quite large.

${ }^{43}$ Across the 22 pairs of OLS and IV estimates in Table II there is a positive but insignificant correlation between the ratio of the IV to the OLS estimates, and the ratio of the standard error of the IV estimate to the OLS estimate. The correlation becomes significant if the Harmon-Walker study is excluded.
} 
estimates of the average marginal return to education. For policy evaluation purposes, however, the average marginal return to schooling in the population may be less relevant than the average return for the group who will be impacted by a proposed reform. In such cases, the best available evidence may be IV estimates of the return to schooling based on similar earlier reforms. The pattern of results in Table II suggests that the OLS estimate, even if upward biased as an estimate of the average causal effect of education, may be a relatively conservative estimate of the causal effect for groups typically affected by supply side reforms.

\section{CONCLUSIONS}

This paper reviews the recent literature that has attempted to measure the causal effect of education on labor market earnings by using institutional features on the supply side of the education system as exogenous determinants of schooling outcomes. The idea of using supply-side shocks to identify demand-side parameters is a cornerstone of structural econometric methodology. Thus, I believe it is helpful to place the returns to education literature in a standard "supply and demand" framework, as first suggested by Becker (1967). Such a framework immediately focuses attention on the rather special conditions that are required in order for the labor market to be characterized by a unique return to education. More generally, different individuals finish their schooling at a point where the marginal return to the last unit of education may be either above or below the average marginal return in the population as a whole.

A supply and demand framework leads to a somewhat richer econometric model for schooling and earnings than is usually adopted in the applied literature. In particular, the implied data generation process for earnings has both a random intercept (reflecting differences across individuals in the amount they could earn at every level of schooling) and a random education slope (reflecting differences across individuals in the marginal return to education). Although one can still estimate a standard human capital earnings function by standard OLS or IV methods, the parameter estimates must be interpreted carefully. Even IV estimation based on ideal instruments (observable factors that are by assumption independent of individual abilities) will typically recover a weighted average of returns to education for people whose education choices were affected by the instrument, rather than the average marginal return to education in the population.

The recent literature that uses supply-side features to instrument schooling choices tends to find IV estimates of the return to schooling that are at least as big and sometimes substantially bigger than the corresponding OLS estimates. In many cases the IV estimates are relatively imprecise, and none of the empirical strategies is based on true randomization. Thus, no individual study is likely to be decisive in the debate over the magnitude of ability biases in OLS estimates of the return to schooling. Taken as a whole, however, the findings 
from the recent IV literature are remarkably consistent with Griliches' (1977) assessment of a much earlier set of studies, and point to a causal effect of education that is as big or bigger than the OLS estimated return, at least for people whose schooling choices are affected by the supply-side innovations that have been studied so far.

Dept. of Economics \# 3880, University of California Berkeley, Berkeley, CA 94720-3880, U.S.A.

Manuscript received April, 1999; final revision received June, 2000.

\section{REFERENCES}

Angrist, Joshua D., Kathryn Graddy, And Guido W. Imbens (1995): "Non-parametric Demand Analysis with an Application to the Demand for Fish," National Bureau of Economic Research Working Paper \#T0178.

ANGRist, Joshua D., And Guido W. Imbens (1995): "Two-Stage Least Squares Estimation of Average Causal Effects in Models with Variable Treatment Intensity," Journal of the American Statistical Association, 90, 431-442.

Angrist, Joshua D., Guido W. Imbens, and Donald B. Rubin (1996): "Identification of Causal Effects Using Instrumental Variables," Journal of the American Statistical Association, 91, 444-472.

Angrist, Joshua D., AND Alan B. Krueger (1991): "Does Compulsory School Attendance Affect Schooling and Earnings," Quarterly Journal of Economics, 106, 979-1014.

- (1992): "Estimating the Payoff to Schooling Using the Vietnam-Era Draft Lottery," NBER Working Paper \#4067.

(1994): "Why Do World War II Veterans Earn More than Non-veterans?" Journal of Labor Economics, 12, 74-97.

- (1995): "Split Sample Instrumental Variables Estimates of the Return to Schooling," Journal of Business and Economics Statistics, 13, 225-235.

- (1999): "Empirical Strategies in Labor Economics," in Handbook of Labor Economics, Volume 3A, ed. by Orley Ashenfelter and David Card. Amsterdam and New York: North Holland.

Angrist, Joshua D., AND Victor Lavy (1999): “Using Maimonides' Rule to Estimate the Effect of Class Size on Scholastic Achievement," Quarterly Journal of Economics, 114, 533-575.

Angrist, Joshua D., AND Whitney K. Newey (1991): "Over-Identification Tests in Earnings Functions with Fixed Effects," Journal of Business and Economic Statistics, 9, 317-323.

Ashenfelter, Orley, Colm Harmon, and Hessel Oosterbeek (1999): "A Review of Estimates of the Schooling/Earnings Relationship, with Tests of Publication Bias," Labour Economics, 6, 453-470.

Ashenfelter, Orley, and Cecilia E. Rouse (1998): "Income, Schooling and Ability: Evidence from a New Sample of Identical Twins," Quarterly Journal of Economics, 113, 253-284.

Beaudry, Paul, AND John DiNARdo (1991): "Implicit Contracts and the Movement of Wages Over the Business Cycle," Journal of Political Economy, 99, 665-688.

Becker, Gary, S. (1964): Human Capital: A Theoretical and Empirical Analysis, with Special Reference to Education. New York: Columbia University Press.

- (1967): Human Capital and the Personal Distribution of Income. Ann Arbor Michigan: University of Michigan Press.

Bound, John, AND DAvid A. Jaeger (1996): “On the Validity of Season of Birth as an Instrument in Wage Equations: A Comment on Angrist and Krueger's 'Does Compulsory School Attendance Affect Schooling and Earnings?'” NBER Working Paper \#5835. 
Bound, John, David A. JAeger, and Regina M. BAKer (1995): "Problems with Instrumental Variables Estimation when the Correlation between the Instruments and the Endogenous Explanatory Variables is Weak," Journal of the American Statistical Association, 90, 443-450.

Brunello, Giorgio, and Raffaele Miniaci (1999): "The Economic Returns to Schooling for Italian Men. An Evaluation Based on Instrumental Variables," Labour Economics, 6, 509-519.

CAllan, Tim, AND COLM HARMON (1999): "The Economic Returns to Schooling in Ireland," Labour Economics, 6, 543-550.

Cameron, Stephen, And Christopher Taber (2000): "Borrowing Constraints and the Returns to Schooling," Unpublished Working Paper, Northwestern University Department of Economics.

CARD, DAVID (1995): "Using Geographic Variation in College Proximity to Estimate the Return to Schooling," in Aspects of Labour Market Behaviour: Essays in Honour of John Vanderkamp, ed. by Louis N. Christofides, E. Kenneth Grant, and Robert Swidinsky. Toronto: University of Toronto Press, 201-222.

- (1999): "The Causal Effect of Education on Earnings," in Handbook of Labor Economics, Volume 3A, ed. by Orley Ashenfelter and David Card. Amsterdam and New York: North Holland.

Card, David, And Thomas Lemieux (2000): "Dropout and Enrollment Trends in the Post-War Period: What Went Wrong in the 1970s?" National Bureau of Economic Research Working Paper 7658.

Conneely, Karen, And Roope Uusitalo (1997): "Estimating Heterogeneous Treatment Effects in the Becker Schooling Model," Unpublished Discussion Paper, Princeton University Industrial Relations Section.

DuFlo, Esther (1998): "Schooling and Labor Market Consequences of School Construction in Indonesia: Evidence from an Unusual Policy Experiment," Unpublished Working Paper, Massachusetts Institute of Technology Department of Economics.

FreEman, Richard B. (1986): "Demand for Education," in Handbook of Labor Economics, ed. by Orley Ashenfelter and Richard Layard. Amsterdam and New York: North Holland.

GAREN, John (1984): "The Returns to Schooling: A Selectivity Bias Approach with a Continuous Choice Variable," Econometrica, 52, 1199-1218.

GrILICHES, ZVI (1977): "Estimating the Returns to Schooling: Some Econometric Problems," Econometrica, 45, 1-22.

HaRmon, Colm, AND IAN Walker (1995): "Estimates of the Economic Return to Schooling for the United Kingdom," American Economic Review, 85, 1278-1286.

Hausman, Jerry A., AND William E. TAYlor (1981): "Panel Data and Unobservable Individual Effects," Econometrica, 49, 1377-1398.

Heckman, James J., AND EdwaRd VytLacil (1998): “Instrumental Variables Methods for the Correlated Random Coefficient Model: Estimating the Rate of Return to Schooling When the Return is Correlated with Schooling," Journal of Human Resources, 23, 974-987.

ICHINO, ANDREA, AND RUdOLF WinTER-EBMER (1998): “The Long-Run Educational Cost of World War II: An Example of Local Average Treatment Effect Estimation," Center for Economic Policy Research Discussion Paper No. 1895.

Imbens, Guido, And Joshua D. Angrist (1994): "Identification and Estimation of Local Average Treatment Effects,” Econometrica, 62, 467-476.

Kane, Thomas J., And Cecilia E. Rouse (1993): "Labor Market Returns to Two- and Four-Year Colleges: Is a Credit a Credit and Do Degrees Matter?” NBER Working Paper \#4268.

Kane, Thomas J., Cecilia E. Rouse, and Douglas Staiger (1999): "Estimating Returns to Education When Schooling is Misreported," National Bureau of Economic Research Working Paper \#7235.

Katz, Lawrence F., and David Autor (1999): "Changes in the Wage Structure and Earnings Inequality," in Handbook of Labor Economics, Volume 3A, ed. by Orley Ashenfelter and David Card. Amsterdam and New York: North Holland.

Keane, Michael, And Kenneth Wolpin (1999): “The Effect of Parental Transfers and Borrowing Constraints on Educational Attainment," Unpublished Manuscript, University of Pennsylvania Department of Economics. 
KLING, JEFFREY (1999): “Interpreting Instrumental Variables Estimates of the Returns to Schooling," Princeton University Industrial Relations Section Working Paper No. 415.

LANG, Kevin (1993): “Ability Bias, Discount Rate Bias, and the Return to Education," Unpublished Discussion Paper, Boston University Department of Economics.

Lemieux, Thomas, AND DAvid Card (1998): "Education, Earnings, and the 'Canadian G.I. Bill'," National Bureau of Economic Research Working Paper \#6718.

Maluccio, JohN (1997): "Endogeneity of Schooling in the Wage Function," Unpublished Manuscript, Yale University Department of Economics.

Meghir, Costas, and Marten Palme (1999): “Assessing the Effect of Schooling on Earnings Using a Social Experiment," Unpublished Working Paper, University College London.

MinCER, JACOB (1974): Schooling, Experience and Earnings. New York: Columbia University Press.

Murphy, Kevin M., AND Robert Topel (1985): "Estimation and Inference in Two-Step Econometric Models," Journal of Business and Economics Statistics, 3, 370-379.

Staiger, Douglas, And James H. Stock (1997): "Instrumental Variables Regression with Weak Instruments," Econometrica, 65, 557-586.

TOPel, Robert H. (1999): "Labor Markets and Economic Growth," in Handbook of Labor Economics, Vol. 3C, ed. by Orley Ashenfelter and David Card. Amsterdam and New York: North Holland.

WiLlis, Robert J. (1986): “Wage Determinants: A Survey and Reinterpretation of Human Capital Earnings Functions," in Handbook of Labor Economics, ed. by Orley Ashenfelter and Richard Layard. Amsterdam and New York: North Holland.

Willis, Robert, AND SHerwin RoSen (1979): "Education and Self-Selection," Journal of Political Economy, 87, S7-S36.

Wooldridge, JefFrey M. (1997): "On Two-Stage Least Squares Estimation of the Average Treatment Effect in a Random Coefficient Model," Economics Letters, 56, 129-133. 
http://www.jstor.org

\section{LINKED CITATIONS}

- Page 1 of 4 -

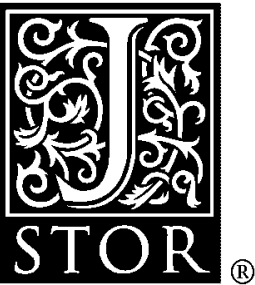

You have printed the following article:

Estimating the Return to Schooling: Progress on Some Persistent Econometric Problems

David Card

Econometrica, Vol. 69, No. 5. (Sep., 2001), pp. 1127-1160.

Stable URL:

http://links.jstor.org/sici?sici=0012-9682\%28200109\%2969\%3A5\%3C1127\%3AETRTSP\%3E2.0.CO\%3B2-Q

This article references the following linked citations. If you are trying to access articles from an off-campus location, you may be required to first logon via your library web site to access JSTOR. Please visit your library's website or contact a librarian to learn about options for remote access to JSTOR.

\section{[Footnotes]}

${ }^{15}$ Instrumental Variables Methods for the Correlated Random Coefficient Model: Estimating the Average Rate of Return to Schooling When the Return is Correlated with Schooling James Heckman; Edward Vytlacil

The Journal of Human Resources, Vol. 33, No. 4. (Autumn, 1998), pp. 974-987.

Stable URL:

http://links.jstor.org/sici?sici=0022-166X\%28199823\%2933\%3A4\%3C974\%3AIVMFTC\%3E2.0.CO\%3B2-3

\section{${ }^{19}$ Education and Self-Selection}

Robert J. Willis; Sherwin Rosen

The Journal of Political Economy, Vol. 87, No. 5, Part 2: Education and Income Distribution. (Oct., 1979), pp. S7-S36.

Stable URL:

http://links.jstor.org/sici?sici=0022-3808\%28197910\%2987\%3A5\%3CS7\%3AEAS\%3E2.0.CO\%3B2-6

\footnotetext{
${ }^{27}$ The Effect of Implicit Contracts on the Movement of Wages Over the Business Cycle: Evidence from Micro Data

Paul Beaudry; John DiNardo

The Journal of Political Economy, Vol. 99, No. 4. (Aug., 1991), pp. 665-688.

Stable URL:

http://links.jstor.org/sici?sici=0022-3808\%28199108\%2999\%3A4\%3C665\%3ATEOICO\%3E2.0.CO\%3B2-0
}

NOTE: The reference numbering from the original has been maintained in this citation list. 
http://www.jstor.org

\title{
LINKED CITATIONS
}

- Page 2 of 4 -

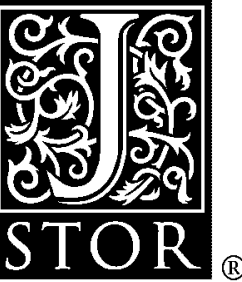

\footnotetext{
${ }^{29}$ Using Maimonides' Rule to Estimate the Effect of Class Size on Scholastic Achievement Joshua D. Angrist; Victor Lavy

The Quarterly Journal of Economics, Vol. 114, No. 2. (May, 1999), pp. 533-575.

Stable URL:

http://links.jstor.org/sici?sici=0033-5533\%28199905\%29114\%3A2\%3C533\%3AUMRTET\%3E2.0.CO\%3B2-3
}

\author{
${ }^{38}$ The Returns to Schooling: A Selectivity Bias Approach with a Continuous Choice Variable \\ John Garen \\ Econometrica, Vol. 52, No. 5. (Sep., 1984), pp. 1199-1218. \\ Stable URL: \\ http://links.jstor.org/sici?sici=0012-9682\%28198409\%2952\%3A5\%3C1199\%3ATRTSAS\%3E2.0.CO\%3B2-U
}

\section{References}

Two-Stage Least Squares Estimation of Average Causal Effects in Models with Variable Treatment Intensity

Joshua D. Angrist; Guido W. Imbens

Journal of the American Statistical Association, Vol. 90, No. 430. (Jun., 1995), pp. 431-442.

Stable URL:

http://links.jstor.org/sici?sici=0162-1459\%28199506\%2990\%3A430\%3C431\%3ATLSEOA\%3E2.0.CO\%3B2-D

\section{Identification of Causal Effects Using Instrumental Variables}

Joshua D. Angrist; Guido W. Imbens; Donald B. Rubin

Journal of the American Statistical Association, Vol. 91, No. 434. (Jun., 1996), pp. 444-455.

Stable URL:

http://links.jstor.org/sici?sici=0162-1459\%28199606\%2991\%3A434\%3C444\%3AIOCEUI\%3E2.0.CO\%3B2-O

\section{Does Compulsory School Attendance Affect Schooling and Earnings?}

Joshua D. Angrist; Alan B. Krueger

The Quarterly Journal of Economics, Vol. 106, No. 4. (Nov., 1991), pp. 979-1014.

Stable URL:

http://links.jstor.org/sici?sici=0033-5533\%28199111\%29106\%3A4\%3C979\%3ADCSAAS\%3E2.0.CO\%3B2-P

NOTE: The reference numbering from the original has been maintained in this citation list. 
http://www.jstor.org

\section{LINKED CITATIONS}

- Page 3 of 4 -

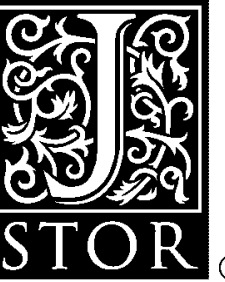

Using Maimonides' Rule to Estimate the Effect of Class Size on Scholastic Achievement Joshua D. Angrist; Victor Lavy

The Quarterly Journal of Economics, Vol. 114, No. 2. (May, 1999), pp. 533-575.

Stable URL:

http://links.jstor.org/sici?sici=0033-5533\%28199905\%29114\%3A2\%3C533\%3AUMRTET\%3E2.0.CO\%3B2-3

Income, Schooling, and Ability: Evidence from a New Sample of Identical Twins

Orley Ashenfelter; Cecilia Rouse

The Quarterly Journal of Economics, Vol. 113, No. 1. (Feb., 1998), pp. 253-284.

Stable URL:

http://links.jstor.org/sici?sici=0033-5533\%28199802\%29113\%3A1\%3C253\%3AISAAEF\%3E2.0.CO\%3B2-5

The Effect of Implicit Contracts on the Movement of Wages Over the Business Cycle:

Evidence from Micro Data

Paul Beaudry; John DiNardo

The Journal of Political Economy, Vol. 99, No. 4. (Aug., 1991), pp. 665-688.

Stable URL:

http://links.jstor.org/sici?sici=0022-3808\%28199108\%2999\%3A4\%3C665\%3ATEOICO\%3E2.0.CO\%3B2-0

Problems with Instrumental Variables Estimation When the Correlation Between the Instruments and the Endogeneous Explanatory Variable is Weak

John Bound; David A. Jaeger; Regina M. Baker

Journal of the American Statistical Association, Vol. 90, No. 430. (Jun., 1995), pp. 443-450.

Stable URL:

http://links.jstor.org/sici?sici=0162-1459\%28199506\%2990\%3A430\%3C443\%3APWIVEW\%3E2.0.CO\%3B2-U

The Returns to Schooling: A Selectivity Bias Approach with a Continuous Choice Variable

John Garen

Econometrica, Vol. 52, No. 5. (Sep., 1984), pp. 1199-1218.

Stable URL:

http://links.jstor.org/sici?sici=0012-9682\%28198409\%2952\%3A5\%3C1199\%3ATRTSAS\%3E2.0.CO\%3B2-U

Estimating the Returns to Schooling: Some Econometric Problems

Zvi Griliches

Econometrica, Vol. 45, No. 1. (Jan., 1977), pp. 1-22.

Stable URL:

http://links.jstor.org/sici?sici=0012-9682\%28197701\%2945\%3A1\%3C1\%3AETRTSS\%3E2.0.CO\%3B2-2

NOTE: The reference numbering from the original has been maintained in this citation list. 
http://www.jstor.org

\section{LINKED CITATIONS \\ - Page 4 of 4 -}

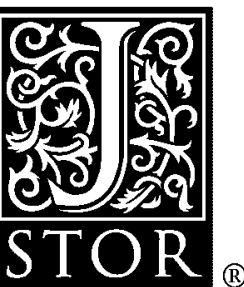

\section{Estimates of the Economic Return to Schooling for the United Kingdom}

Colm Harmon; Ian Walker

The American Economic Review, Vol. 85, No. 5. (Dec., 1995), pp. 1278-1286.

Stable URL:

http://links.jstor.org/sici?sici=0002-8282\%28199512\%2985\%3A5\%3C1278\%3AEOTERT\%3E2.0.CO\%3B2-C

\section{Panel Data and Unobservable Individual Effects}

Jerry A. Hausman; William E. Taylor

Econometrica, Vol. 49, No. 6. (Nov., 1981), pp. 1377-1398.

Stable URL:

http://links.jstor.org/sici?sici=0012-9682\%28198111\%2949\%3A6\%3C1377\%3APDAUIE\%3E2.0.CO\%3B2-3

Instrumental Variables Methods for the Correlated Random Coefficient Model: Estimating the Average Rate of Return to Schooling When the Return is Correlated with Schooling James Heckman; Edward Vytlacil

The Journal of Human Resources, Vol. 33, No. 4. (Autumn, 1998), pp. 974-987.

Stable URL:

http://links.jstor.org/sici?sici=0022-166X\%28199823\%2933\%3A4\%3C974\%3AIVMFTC\%3E2.0.CO\%3B2-3

\section{Identification and Estimation of Local Average Treatment Effects}

Guido W. Imbens; Joshua D. Angrist

Econometrica, Vol. 62, No. 2. (Mar., 1994), pp. 467-475.

Stable URL:

http://links.jstor.org/sici?sici=0012-9682\%28199403\%2962\%3A2\%3C467\%3AIAEOLA\%3E2.0.CO\%3B2-2

\section{Instrumental Variables Regression with Weak Instruments}

Douglas Staiger; James H. Stock

Econometrica, Vol. 65, No. 3. (May, 1997), pp. 557-586.

Stable URL:

http://links.jstor.org/sici?sici=0012-9682\%28199705\%2965\%3A3\%3C557\%3AIVRWWI\%3E2.0.CO\%3B2-Z

\section{Education and Self-Selection}

Robert J. Willis; Sherwin Rosen

The Journal of Political Economy, Vol. 87, No. 5, Part 2: Education and Income Distribution. (Oct., 1979), pp. S7-S36.

Stable URL:

http://links.jstor.org/sici?sici=0022-3808\%28197910\%2987\%3A5\%3CS7\%3AEAS\%3E2.0.CO\%3B2-6

NOTE: The reference numbering from the original has been maintained in this citation list. 